\title{
Selective Vapor Phase Hydrodeoxygenation of Anisole to Benzene on Molybdenum Carbide Catalysts
}

\author{
Wen-Sheng Lee, Zhenshu Wang, Ryan Wu, Aditya Bhan* \\ Department of Chemical Engineering and Materials Science, University of Minnesota, Minneapolis, MN 55455 \\ *Corresponding Author: E-mail: abhan@umn.edu; Fax: (+1) 612-626-7246
}

(C) 2014. This manuscript version is made available under the Elsevier user license http://www.elsevier.com/open-access/userlicense/1.0/ 


\begin{abstract}
Vapor phase hydrodeoxygenation (HDO) of anisole over $\mathrm{Mo}_{2} \mathrm{C}$ catalysts at low temperatures (420-520 K) and ambient pressures showed (1) remarkable selectivity for C-O bond cleavage, giving benzene selectivity $>90 \%$ amongst $\mathrm{C}_{6}{ }^{+}$products (2) high hydrogen efficiency for the HDO reaction as indicated by low cyclohexane selectivity $(<9 \%)$, and (3) good stability over $\sim 50 \mathrm{~h}$. Methane selectivity increased at the expense of methanol selctivity as anisole conversion increased, suggesting that the phenolic $\mathrm{C}-\mathrm{O}$ bond was cleaved preferentially. The concurrent near half/zero order dependence of benzene synthesis rates on $\mathrm{H}_{2}$ /anisole pressure, and the preferential inhibition of benzene synthesis rates upon introduction of $\mathrm{CO}$ relative to isotopic $\mathrm{HD}$ exchange suggests that catalytic sites for $\mathrm{H}_{2}$ activation are distinct from those required for activation of anisole. The involvement of metallic sites on $\mathrm{Mo}_{2} \mathrm{C}$ catalysts for this reaction was demonstrated by the nearly invariant benzene synthesis rate per $\mathrm{CO}$ chemisorption site.
\end{abstract}

Keywords: lignin upgrading, anisole, benzene, molybdenum carbide, hydrodeoxygenation 


\section{Introduction}

Utilization of biogenic sources as an alternative carbon feedstock to produce fuels and chemicals has drawn a lot of attention because of sustainability and environmental concerns [1-3]. In this context, the lignin fraction of lignocellulosic biomass represents the most viable source to produce aromatic compounds. Hydrodeoxygenation (HDO) of phenolic ethers derived from lignin-monomers results in the synthesis of aromatic compounds such as benzene, toluene, and xylene (BTX) [4-7]. High selectivity to cleavage of the phenolic $\mathrm{C}-\mathrm{O}$ bond, which gives aromatics products, is desired, but concurrently challenging because of its strong bond strength (422-468 $\left.\mathrm{kJ}^{\text {mole }}{ }^{-1}\right)$ [1]. Severe reaction conditions with both high reaction temperature $(500-700 \mathrm{~K})$, which facilitates phenolic C-O bond cleavage [1, 8-10] and high hydrogen pressure (1-30 MPa), which alleviates catalyst deactivation by reducing coke formation $[8,11-13]$ are typically used for HDO of phenolic compounds to give aromatics products, which accompanies potential issues such as (i) excess hydrogen consumption and/or loss of aromaticity via unwanted hydrogenation, and/or (ii) reduction of the carbon chain length via hydrogenolysis reactions, and/or (iii) low selectivity to desired deoxygenated aromatics due to other side reactions such as alkylation/transalkylation promoted by high reaction temperatures $[14,15]$.

Anisole has been widely chosen as a model compound for lignin-derived phenolics because it contains a methoxyl group $\left(-\mathrm{OCH}_{3}\right)$, one of the major oxygen-containing 
functional groups found in lignin-derived monomers [12, 15-21]. Low selectivity $(<25 \%)$ to the desired deoxygenated aromatics (i.e., benzene) but high selectivity ( $>40 \%)$ to phenol was found for anisole HDO with conventional hydrotreating Co-Mo sulfide catalysts (either in the liquid or vapor phase) at different conditions with temperatures ranging from 523 to $560 \mathrm{~K}$ and total pressure ranging from 1.5 to $50 \mathrm{MPa}[18,22,23]$, suggesting that Co-Mo based catalysts preferentially break the weaker aliphatic C-O bond ( $\left.\sim 339 \mathrm{~kJ} \mathrm{~mole}^{-1}\right)$, not the phenolic C-O bond, in anisole. Transition metal phosphides, a potential new class of hydroprocessing catalysts [24-26], have also been investigated $\left(\mathrm{Ni}_{2} \mathrm{P} / \mathrm{SiO}_{2}, \mathrm{MoP} / \mathrm{SiO}_{2}\right.$ and $\left.\mathrm{NiMoP} / \mathrm{SiO}_{2}\right)$ for anisole $\mathrm{HDO}$ in a fixed bed reactor [17]. While the selectivity to deoxygenated products (benzene and cyclohexane) can reach almost $\sim 100 \%$ at $573 \mathrm{~K}$ and $1.5 \mathrm{MPa}$, the benzene selectivity was found to be less than $20 \%$, suggesting inefficient usage of $\mathrm{H}_{2}$ for the HDO reaction. Similarly, benzene selectivity was found to be only $\sim 30-46 \%$ at $498-548 \mathrm{~K}$ under 50 atm $\mathrm{H}_{2}$ when using copper chromite as a catalyst for liquid phase anisole HDO [16]. Vapor phase anisole $\mathrm{HDO}$ over noble metal catalysts such as $\mathrm{Pt} / \mathrm{Al}_{2} \mathrm{O}_{3}$ at $573 \mathrm{~K}$ and near ambient pressure $(\sim 140 \mathrm{kPa})$ resulted in benzene selectivity as low as $\sim 4.4 \%$ and high phenol selectivity $(\sim 65 \%)$ [21]. Pt-Sn bimetallic catalysts showed higher benzene yield than either Pt or Sn monometallic catalysts for vapor phase guaiacol HDO reactions, however, these bimetallic formulations still resulted in aromatic yields less than $50 \%$ for vapor phase anisole HDO reactions at $673 \mathrm{~K}$ and atmospheric pressure [12].

High selectivity to deoxygenation products with selectivity to benzene $\sim 50 \%$, toluene $\sim 25 \%$, and xylene $\sim 10 \%$ at $\sim 673 \mathrm{~K}$ under $1 \mathrm{~atm}$, however, was reported when an 
acidic function (H-BEA) was introduced together with a metal function (Pt) [15]. Hicks and coworkers recently reported that high selectivity to benzene amongst $\mathrm{C}_{6}^{+}$products ( $90 \%)$ for anisole HDO reactions in the liquid phase with toluene as a solvent could be obtained using bimetallic FeMo phosphide (FeMoP) catalysts, however, high hydrogen pressures $\sim 2.1 \mathrm{MPa}$ and high reaction temperatures $\sim 673 \mathrm{~K}$ were required to accomplish this selective deoxygenation [19]. $\mathrm{MoO}_{3}$, which showed the highest specific rates for acetone $\mathrm{HDO}$ amongst other reducible metal oxides such as $\mathrm{V}_{2} \mathrm{O}_{5}, \mathrm{Fe}_{2} \mathrm{O}_{3}, \mathrm{CuO}$, and $\mathrm{WO}_{3}$ via a reverse Mars-van Krevelen mechanism, was also tested for vapor phase anisole $\mathrm{HDO}$ at $673 \mathrm{~K}$ under ambient pressure [27]. A mixture of deoxygenated aromatics was observed in which the selectivity of benzene, toluene, xylene, and alkylbenzenes was $\sim 60 \%, \sim 20 \%, \sim 6.5 \%$, and $\sim 13 \%$ respectively [27]. No observation of sequential hydrogenation products of the aforementioned aromatics was reported, implying that this process is hydrogen efficient [27].

Recently, transition metal carbides have been reported to selectively remove oxygen from $\mathrm{C}_{2}-\mathrm{C}_{3}$ oxygenates [28, 29], vegetable oils [30], stearic acid [4], and guaiacol [31]. Herein, we report that $\mathrm{Mo}_{2} \mathrm{C}$ is a selective $\mathrm{HDO}$ catalyst for phenyl ethers at low temperatures ( 420-520 K) and under atmospheric pressure with good catalyst stability over the course of $\sim 50 \mathrm{~h}$, in which benzene can be formed almost exclusively with $>90 \%$ selectivity amongst $\mathrm{C}_{6}^{+}$products. The high hydrogen efficiency of this process is evidenced by the low selectivity $(<9 \%)$ to cyclohexane in successive hydrogenation reactions of benzene even at high hydrogen-to-oxygenate molar ratios $(\sim 70,000)$ in the reactant feed. Plausible reaction mechanisms in which two distinct catalytic sites are 
involved for vapor phase anisole $\mathrm{HDO}$ on $\mathrm{Mo}_{2} \mathrm{C}$ catalysts are proposed based on detailed kinetic measurements performed in this work. Metallic sites on $\mathrm{Mo}_{2} \mathrm{C}$ catalysts are involved in the reaction as inferred from the near invariance in benzene synthesis rates normalized by the number of catalytic centers measured by ex situ $\mathrm{CO}$ chemisorption, although the requirement of carbidic or oxycarbidic sites for HDO chemistry remains ambiguous at this point.

\section{Experimental Methods}

\subsection{Catalyst synthesis}

$\mathrm{Mo}_{2} \mathrm{C}$ catalysts were prepared based on a prior report with ammonium molybdate tetrahydrate $\left.\left(\mathrm{NH}_{4}\right)_{6} \mathrm{Mo}_{7} \mathrm{O}_{24} \cdot 4 \mathrm{H}_{2} \mathrm{O}\right)$ as a precursor $[28,32] . \mathrm{Mo}_{2} \mathrm{C}$ catalysts with varying number of $\mathrm{CO}$ adsorption sites were obtained using varying temperature and flow rate protocols that are described in detail below. An appropriate amount (0.6-6 g) of ammonium molybdate tetrahydrate (sieved, $177-400 \mu \mathrm{m}$, Sigma, $99.98 \%$, trace metal basis; typically $\sim 0.6 \mathrm{~g}$ ) was loaded in a tubular quartz reactor (I.D. $10 \mathrm{~mm}$ ) and purged with a desired total flow rate $\left(1.09-2.93 \mathrm{~cm}^{3} \mathrm{~s}^{-1}\right.$; typically $\left.2.93 \mathrm{~cm}^{3} \mathrm{~s}^{-1}\right)$, consisting of either 15/85 vol\% of $\mathrm{CH}_{4}$ (Matheson, 99.97\%) and $\mathrm{H}_{2}$ (Minneapolis Oxygen, 99.999\%) mixture or pure $\mathrm{H}_{2}$ at room temperature (RT) for about 1-5 min (typically in $\mathrm{CH}_{4} / \mathrm{H}_{2}$ mixture). The reactor was then heated in a three-zone split tube furnace (Series 3210, Applied Test System) from RT to the first target temperature ( 618-623 K, typically 623 $\mathrm{K}$ ) within $1.5 \mathrm{~h}$, and the temperature was then held for $12-24 \mathrm{~h}$. Subsequently, the sample 
was heated in a $\mathrm{CH}_{4} / \mathrm{H}_{2}(15 / 85$ vol\%) gas mixture (the gas mixture either remained unchanged or $\mathrm{CH}_{4}$ was added to the existing pure $\mathrm{H}_{2}$ flow to give the desired composition) to the final target temperature ( 863-978 K, typically $863 \mathrm{~K})$ within $1.5 \mathrm{~h}$ and held at the final temperature for 2-6 h (typically $2 \mathrm{~h}$ ) and then cooled down to RT in the $\mathrm{CH}_{4} / \mathrm{H}_{2}(15 / 85$ vol\%) gas mixture flow. The resulting material was then treated in a flowing $1 \% \mathrm{O}_{2} / \mathrm{He}$ mixture (Matheson, Certified Standard Purity) at $\sim 1.67-3.33 \mathrm{~cm}^{3} \mathrm{~s}^{-1}$ for at least $2 \mathrm{~h}$ before being removed from the reactor to passivate the carbidic surface [33]. Thus, a typical protocol for the $\mathrm{Mo}_{2} \mathrm{C}$ catalyst preparation (sample\#8 in Table 1), "CH $4 / \mathrm{H}_{2}-\mathrm{RT}(1.5 \mathrm{~h})-623 \mathrm{~K}[12 \mathrm{~h}](1.5 \mathrm{~h})-863 \mathrm{~K}[2 \mathrm{~h}]-$ cool", represents that the ammonium molybdate tetrahydrate in the reactor was exposed to a gas environment of $\mathrm{CH}_{4} / \mathrm{H}_{2}$ mixture and heated up to $623 \mathrm{~K}$ within $1.5 \mathrm{~h}$ and held at $623 \mathrm{~K}$ for $12 \mathrm{~h}$. After that, the temperature was increased to $863 \mathrm{~K}$ within $1.5 \mathrm{~h}$. Finally, the reactor was held at $863 \mathrm{~K}$ for $2 \mathrm{~h}$ and then cooled down to RT. Even though the preparation conditions were carefully controlled in this work, different batches of $\mathrm{Mo}_{2} \mathrm{C}$ catalysts may have small variations in their physical/chemical properties because the degree of carburization as well as the amount of carbon deposition was found to be sensitive to the carburization conditions $[34,35]$. Therefore, samples \#1-8 listed in Table 1 consisted of multiple batches of $\mathrm{Mo}_{2} \mathrm{C}$ synthesized with the corresponding preparation conditions to create a representative $\mathrm{Mo}_{2} \mathrm{C}$ catalyst that shares a set of physical/chemical properties. Sample \#9 in Table 1, however, was prepared by recarburizing a mixture of multiple batches of $\mathrm{Mo}_{2} \mathrm{C}$ with different amounts of $\mathrm{CO}$ chemisorption sites at $323 \mathrm{~K}(\sim 6 \mathrm{~g})$ in a $\mathrm{CH}_{4} / \mathrm{H}_{2}$ mixture $\left(14 / 86\right.$ vol\%, $\left.\sim 9.66 \mathrm{~cm}^{3} \mathrm{~s}^{-1}\right)$ using a temperature protocol shown in Table 1 . We note that the fresh, passivated sample was stored in a vial (ambient conditions) and 
exposed to air before the kinetic measurements and aged $<1$ month prior to the characterization discussed below.

$\mathrm{Pd} / \mathrm{Al}_{2} \mathrm{O}_{3}(\sim 1 \mathrm{wt} \% \mathrm{Pd})$ catalysts were prepared by an incipient wetness method in which $\sim 1$ g of alumina (Sasol North America Inc., pretreated in a flow of dry air (ultrapure, Minneapolis Oxygen) with a total flow rate $\sim 1.67 \mathrm{~cm}^{3} \mathrm{~s}^{-1}$ at $723 \mathrm{~K}\left(0.012 \mathrm{~K} \mathrm{~s}^{-}\right.$

${ }^{1}$ ) for $4 \mathrm{~h}$ prior to usage) was impregnated with an appropriate amount of $\mathrm{Pd}$ solution $\left(\mathrm{Pd}\left(\mathrm{NO}_{3}\right)_{2} 2 \mathrm{H}_{2} \mathrm{O}, \sim 40 \%\right.$ metal basis, Sigma Aldrich). After impregnation, samples were dried in a static oven at $\sim 363 \mathrm{~K}$ overnight, followed by treatment in a flow of dry air $\left(\sim 1.67 \mathrm{~cm}^{3} \mathrm{~s}^{-1}\right)$ at $363 \mathrm{~K}\left(0.012 \mathrm{~K} \mathrm{~s}^{-1}\right)$ for $9 \mathrm{~h}$ and subsequently heated at $823 \mathrm{~K}(0.025 \mathrm{~K}$ $s^{-1}$ ) for $4 h$.

\subsection{Materials characterization}

Unless otherwise mentioned, a representative fresh, passivated $\mathrm{Mo}_{2} \mathrm{C}$ sample, sample\#8 in Table 1, was used for the characterization protocol discussed below. The bulk structures of both spent and fresh samples were determined using X-ray diffraction (XRD, Bruker D8 Discover 2D x-ray diffractometer with a two-dimensional VÅNTEC500 detector, $\mathrm{Cu} K_{\alpha}$ x-ray radiation with a graphite monochromator, and a $0.5 \mathrm{~mm}$ point collimator). The sample was drop casted on a $\mathrm{SiO}_{2}$ zero-background holder and measured in three measurement frames at $30^{\circ}(2 \theta), 60^{\circ}(2 \theta)$ and $90^{\circ}(2 \theta)$ with a $600 \mathrm{~s}$ frame $^{-1}$ dwell $\left(\Delta 2 \theta\right.$ frame width of $\left.35^{\circ}(2 \theta)\right)$. Two-dimensional images were then converted to one-dimensional intensity vs. $2 \theta$ for analysis. The crystallite size of the 
sample was estimated using the Scherrer equation [35]. The particle morphologies of the sample were characterized via transmission electron microscopy (TEM FEI Tecnai T12, $120 \mathrm{KeV})$. For TEM sample preparation, the $\mathrm{Mo}_{2} \mathrm{C}$ catalyst was sonicated in dimethylformamide (DMF, Sigma, 99.8\% ACS reagent) for $2 \mathrm{~h}$ and a drop was placed onto a holey-carbon $\mathrm{Cu}$ grid and then dried at $353 \mathrm{~K}$ in a vacuum oven overnight prior to the TEM analysis. The BET surface area $\left(\mathrm{S}_{\mathrm{g}}\right)$, pore volume, and mesopore size distribution (obtained by Barrett-Joyner-Halenda $(\mathrm{BJH})$ analysis at desorption branch) were measured using $\mathrm{N}_{2}$ adsorption/desorption isotherms (Micromeritics ASAP 2020). The sample was degassed $\left(<6 \mu \mathrm{m} \mathrm{Hg}\right.$ ) at $523 \mathrm{~K}$ for at least $4 \mathrm{~h}$ before $\mathrm{N}_{2}$ adsorption. $\mathrm{CO}$ (Matheson, 99.5\%) chemisorption uptakes were measured at $323 \mathrm{~K}$ using a Micromeritics ASAP 2020 instrument. CO chemisorption measurements for all samples shown in Table 1 were done following the procedure described below. The cell loaded with the $\mathrm{Mo}_{2} \mathrm{C}$ catalyst (0.05-0.2 g) was first evacuated at $383 \mathrm{~K}(\sim 2 \mu \mathrm{m} \mathrm{Hg})$ for $0.5 \mathrm{~h}$, and then treated in $\mathrm{H}_{2}$ at $723 \mathrm{~K}$ for $2 \mathrm{~h}$, followed by degassing $(\sim 2 \mu \mathrm{m} \mathrm{Hg})$ at $723 \mathrm{~K}$ for $2 \mathrm{~h}$. The sample was subsequently cooled to $323 \mathrm{~K}$ prior to the first adsorption isotherm measurement (between $100-450 \mathrm{~mm} \mathrm{Hg})$. The cell was then degassed $(\sim 2 \mu \mathrm{m} \mathrm{Hg})$ to remove weakly adsorbed species prior to the second isotherm. Both isotherms were extrapolated to zero pressure to determine the total (from the first isotherm) and weakly adsorbed (from the second isotherm) species. The amount of irreversibly or strongly adsorbed species was obtained by the difference between two extrapolated values [35, 36]. The procedure for $\mathrm{H}_{2}$ chemisorption of $1 \mathrm{wt} \% \mathrm{Pd} / \mathrm{Al}_{2} \mathrm{O}_{3}$ catalysts used for $\mathrm{H}_{2}-\mathrm{D}_{2}-\mathrm{CO}$ titration experiments (section 3.3) is similar to that for the $\mathrm{CO}$ chemisorption of $\mathrm{Mo}_{2} \mathrm{C}$ catalysts except the $\mathrm{Pd}$ sample was pretreated in $\mathrm{H}_{2}$ at $523 \mathrm{~K}$ for $1 \mathrm{~h}$ prior to $\mathrm{H}_{2}$ chemisorption at $323 \mathrm{~K}$ and 
irreversibly adsorbed $\mathrm{H}_{2}$ was used to calculate the Pd metal dispersion by assuming a hydrogen-to-metal stoichiometry of one.

\subsection{Kinetic measurements of vapor phase anisole $\mathrm{HDO}$ on $\mathrm{Mo}_{2} \mathrm{C}$ catalysts}

Vapor phase anisole hydrodeoxygenation (HDO) rates were measured using a tubular quartz reactor (I.D. $10 \mathrm{~mm}$ ) with an outer thermowell at the bottom of the reactor for holding a thermocouple to monitor reaction temperature. Catalysts $(0.03-0.14 \mathrm{~g})$ were treated in pure $\mathrm{H}_{2}\left(\sim 1.67 \mathrm{~cm}^{3} \mathrm{~s}^{-1}\right)$ at $\sim 750 \mathrm{~K}$ for $1 \mathrm{~h}$ and cooled down to a typical reaction temperature $\sim 423 \mathrm{~K}$ before introducing the reaction mixture $\left(\sim 1.67 \mathrm{~cm}^{3} \mathrm{~s}^{-1}\right)$ consisting of $\sim 0.14 / \mathrm{bal}$ (vol\%) of anisole and $\mathrm{H}_{2}$. Anisole (Sigma, 99\%, ReagentPlus) was added using a syringe pump (KD Scientific, Model 100). All flow lines were heated to at least $373 \mathrm{~K}$ via resistive heating to prevent condensation of effluents sent to a mass spectrometer (MKS Cirrus 200 Quadrupole MS system) and a gas chromatograph (Agilent 6890) equipped with a methyl-siloxane capillary column (HP-1, $50 \mathrm{~m} \times 320 \mu \mathrm{m}$ $\times 0.52 \mu \mathrm{m})$ connected to a flame ionization detector (FID). The concentration of analytes from reactor effluents was quantified with an external standard method in which the corresponding GC calibration curves with $\mathrm{R}^{2}$ values $>0.96$ and at least 4 different concentrations ensured precise measurement of the concentration of products of interest. The carbon balance was typically better than $92 \%$. The anisole conversion and product selectivity are calculated as follows: 
Anisole conversion $=($ sum of the carbon in products $)$ out $/($ moles of carbon in anisole $)$ in; $\mathrm{C}_{6}^{+}$product selectivity $=\left(\right.$moles of $\mathrm{C}_{6}^{+}$product $\left.\mathrm{i}\right) /\left(\sum\right.$ moles of $\mathrm{C}_{6}{ }^{+}$products $)$.

$\mathrm{C}_{1}$ product selectivity $=($ moles of methane or methanol $) /($ moles of methane + moles of methanol)

Kinetic studies were conducted in a differential reactor bed in which anisole conversion was controlled to be $<15 \%$. The absence of heat and external mass transfer limitations was confirmed by estimating Mears' criteria (Table S1, SI). The benzene turnover rate was independent of linear velocities of the reactants (Fig. S1, SI), demonstrating that the reaction rate was not limited by external mass transfer. Internal mass transfer limitations can be neglected because the estimated Thiele modulus was significantly less than 1 (Table S2, SI).

$\mathrm{H}_{2}-\mathrm{D}_{2}$ exchange reactions were performed by flowing a gas mixture $\left(\sim 1.67 \mathrm{~cm}^{3} \mathrm{~s}^{-1}\right)$ consisting of anisole $/ \mathrm{D}_{2} / \mathrm{H}_{2} / \mathrm{Ar}(\mathrm{vol} \%)=\sim 0.12 / 40 / 40 / \mathrm{bal}$ to a reactor packed with a mixture of $0.0221 \mathrm{~g}$ of $\mathrm{Mo}_{2} \mathrm{C}$ catalysts (sample \#10 in Table 1) and $\sim 0.45 \mathrm{~g}$ quartz sand (washed with $1 \mathrm{M} \mathrm{HNO}_{3}$ solution and treated in a flow of air at $1073 \mathrm{~K}$ for $2 \mathrm{~h}$ prior to usage), which had been tested under standard reaction conditions (STD, reaction mixture consisting of anisole $/ \mathrm{H}_{2}(\mathrm{vol} \%)=0.12 / \mathrm{bal}$ with total flow rate $\sim 1.67 \mathrm{~cm}^{3} \mathrm{~s}^{-1}$ at $406 \mathrm{~K}$ ) for $\sim 2 \mathrm{~h}$. The net rates of H/D exchange were measured by using online mass spectrometry (MS, MKS Cirrus 200 Quadrupole MS system). The mass spectrometer was calibrated by flowing a gas mixture with varying $\mathrm{H}_{2} / \mathrm{D}_{2}$ compositions through a reactor packed with a mixture of $\sim 0.2 \mathrm{~g} \mathrm{Pd} / \mathrm{Al}_{2} \mathrm{O}_{3}$ catalysts (Pd loading $\sim 1 \mathrm{wt} \%$, and metal dispersion $\sim 12 \%$ 
by $\mathrm{H}_{2}$ chemisorption measured at $323 \mathrm{~K}$ ) and $\sim 1 \mathrm{~g}$ quartz sand at $\sim 463 \mathrm{~K}$ to obtain the corresponding equilibrated $\mathrm{H}_{2} / \mathrm{D}_{2}$ mixture. The Pd catalysts were activated by flowing $\mathrm{H}_{2}\left(\sim 1.67 \mathrm{~cm}^{3} \mathrm{~s}^{-1}\right)$ at $573 \mathrm{~K}$ for $1 \mathrm{~h}$ with a ramping rate $\sim 0.05 \mathrm{~K} \mathrm{~s}^{-1}$ from $\mathrm{RT}$ before calibrating the mass spectrometer for HD. The error associated with HD quantification by online mass spectrometry, calculated from 11 independent measurements of HD response factor, was found to be $<10 \%$. The measured reversibility of $\mathrm{H} / \mathrm{D}$ exchange, $\eta_{\mathrm{HD}}$, was estimated to be $\sim 0.1$. Rates of H/D exchange are reported as forward rates of H/D exchange, which were obtained by dividing the net rate of H/D exchange by $\left(1-\eta_{\mathrm{HD}}\right)$.

\section{Results and Discussion}

\subsection{Characterization of $\mathrm{Mo}_{2} \mathrm{C}$}

The absence of peaks assigned to the $\mathrm{MoO}_{3}$ crystalline phase, as shown in Figure 1, suggests that bulk carburization was achieved. $\beta-\mathrm{Mo}_{2} \mathrm{C}$ (Joint Committee on Powder Diffraction Standards, No. 35-0787, $2 \theta$ peaks at $\sim 34.355^{\circ}(100), 37.979^{\circ}(002), 39.393^{\circ}$ $(101), 52.124^{\circ}(102), 61.529^{\circ}(110), 69.567^{\circ}(103), 74.647^{\circ}(112)$ and $\left.75.514^{\circ}(201)\right)$ was identified as the major carbidic phase and $\alpha-\mathrm{MoC}_{1-\mathrm{x}}$ as the minor phase based on the comparison of the observed XRD peak intensities from both phases. The materials are, therefore, referred to as $\mathrm{Mo}_{2} \mathrm{C}$ formulations because the $\mathrm{Mo} / \mathrm{C}$ molar ratio is near two in both phases. An impurity phase which contributed the signal at $\sim 26^{\circ}(2 \theta)$, however, was also found in the fresh, passivated $\mathrm{Mo}_{2} \mathrm{C}$ catalyst (Fig. 1). Both $\mathrm{MoO}_{2}$ and $\mathrm{Mo}(\mathrm{CO})_{6}$ might be the source of the impurity based on the comparison between the observed XRD 
pattern and the references of $\mathrm{MoO}_{2}$ (JCPDS No. 32-0671) and $\mathrm{Mo}(\mathrm{CO})_{6}$ (JCPDS No. 120691) (see Fig. S2(a) in the SI). Although our XRD analysis does not allow us to distinguish between $\mathrm{Mo}(\mathrm{CO})_{6}$ and $\mathrm{MoO}_{2}$, the impurity could be residual $\mathrm{MoO}_{2}$ with poor crystallinity since the formation of $\mathrm{MoO}_{2}$ was observed during the carburization process with ammonium molybdate as the $\mathrm{Mo}_{2} \mathrm{C}$ precursor by Djéga-Mariadassou and coworkers [34]. The observation of two different phases, $\beta-\mathrm{Mo}_{2} \mathrm{C}$ and $\alpha-\mathrm{MoC}_{1-\mathrm{x}}$, and the impurity phase at $\sim 26^{\circ}(2 \theta)$ for the $\mathrm{Mo}_{2} \mathrm{C}$ catalyst synthesized in this work is consistent with those reported by Thompson and coworkers [32]. The peak at $\sim 26^{\circ}(2 \theta)$, however, was not observed for $\mathrm{Mo}_{2} \mathrm{C}$ catalysts prepared by re-carburization (sample \#9 in Table 1, passivated prior to XRD measurement) in a $\mathrm{CH}_{4} / \mathrm{H}_{2}$ mixture flow $\left(14 / 86 \mathrm{vol} \%, \sim 9.66 \mathrm{~cm}^{3}\right.$ $\mathrm{s}^{-1}$ ) as shown in Fig. S2(b) in the SI. The presence of this impurity phase, however, was found to have a negligible effect on the catalytic performance in vapor phase anisole HDO, as inferred from similar benzene synthesis rates for sample \#8 and \#9 ( 3 $\times 10^{-4}$ mole $\mathrm{s}^{-1}$ mole $\mathrm{CO}_{\text {site }}{ }^{-1}$, Table 2), as discussed in section 3.3.

The crystallite size of $\beta-\mathrm{Mo}_{2} \mathrm{C}$ for the fresh, passivated $\mathrm{Mo}_{2} \mathrm{C}$ catalyst (sample\#8 in Table 1), estimated using the Scherrer equation for the $2 \theta$ peak at $\sim 52^{\circ}$ (the peak intensity has contributions only from $\beta-\mathrm{Mo}_{2} \mathrm{C}$ phase), was found to be $\sim 3.3 \mathrm{~nm}$, which is comparable to that reported by Boudart and coworkers for $\mathrm{Mo}_{2} \mathrm{C}$ catalysts $(\sim 5.8 \mathrm{~nm})$ prepared using $\mathrm{MoO}_{3}$ as the precursor [35]. The BET surface area and the amount of irreversible chemisorbed $\mathrm{CO}$ at $\sim 323 \mathrm{~K}$ for a typical fresh, passivated $\mathrm{Mo}_{2} \mathrm{C}$ catalyst (sample \#8 in Table 1) were $\sim 116 \mathrm{~m}^{2} \mathrm{~g}^{-1}$ and $220 \mu$ mole $\mathrm{g}^{-1}$ (STP) respectively, which is in good agreement with results reported by Thompson and coworkers [32]. Porous 
features of a typical fresh, passivated $\mathrm{Mo}_{2} \mathrm{C}$ catalysts were evidenced by: (1) the existence of a hysteresis loop observed in the relative pressure $\left(\mathrm{P} / \mathrm{P}^{0}\right)$ range of $0.4-0.8$, characteristic of multilayer adsorption occurring inside mesopores in the $\mathrm{N}_{2}$ adsorption isotherms, as shown in Figure 2; and (2) the observed contrast regions inside a representative $\mathrm{Mo}_{2} \mathrm{C}$ particle from TEM analysis, as shown in Figure 3. Furthermore, the theoretical (100) interplanar distance matched the spacing of the lattice fringes, confirming the presence of the $\beta-\mathrm{Mo}_{2} \mathrm{C}$ structure. The average mesopore diameter and pore volume (at $\mathrm{P} / \mathrm{P}^{0} \sim 0.99$ ) were found to be $\sim 6.4 \mathrm{~nm}$ (BJH desorption branch) and 0.14 $\mathrm{cm}^{3} \mathrm{~g}^{-1}$ respectively. A typical fresh, passivated $\mathrm{Mo}_{2} \mathrm{C}$ catalyst was in polycrystalline form as evidenced by the arrangement of discrete spots observed in the selected area electron diffraction (SAED) of a typical $\mathrm{Mo}_{2} \mathrm{C}$ particle (not shown) consistent with the results reported by Bell and coworkers [37]. The much larger particle size (Dp 70 nm, estimated by BET surface area $\left(S_{g}\right)$ using the equation Dp $\sim 6\left(\rho \times S_{g}\right)^{-1}$ where $\rho$ is the bulk density of the $\mathrm{Mo}_{2} \mathrm{C}$ catalyst, reported to be around $\sim 760 \mathrm{~kg} \mathrm{~m}^{-3}$ [38]), as compared to the crystallite size $(\sim 3.3 \mathrm{~nm})$ determined by $\mathrm{XRD}$, also suggests the synthesized $\mathrm{Mo}_{2} \mathrm{C}$ catalyst is polycrystalline.

\subsection{Kinetics of vapor phase anisole $\mathrm{HDO}$ on $\mathrm{Mo}_{2} \mathrm{C}$ catalysts}

Figure 4 shows the conversion and selectivity for vapor phase anisole HDO on a $\mathrm{Mo}_{2} \mathrm{C}$ catalyst (sample \#8 in Table 1 ) over a temperature range of $420-520 \mathrm{~K}$ at ambient pressure. The time-on-stream behavior of the catalyst showed that $<20 \%$ deactivation occurred after two temperature cycles $(420 \mathrm{~K}-520 \mathrm{~K}-472 \mathrm{~K})$ over a time period of $\sim 50$ 
h, implying $\mathrm{Mo}_{2} \mathrm{C}$ catalysts are significantly more stable than Pt- or CoMo- based catalysts, which typically showed $>20 \%$ deactivation within $\sim 5 \mathrm{~h}[12,15,18]$. The selectivities of all major products (benzene, cylohexane (Figure 4(b)), methane, and methanol (Figure 4(c))) at a given temperature (e.g. $472 \mathrm{~K}$ ) during the second temperature cycle, were found to be the same as those measured during the first temperature cycle, indicating that catalyst deactivation was caused by a change in the number and not the chemistry or identity of the active sites.

There are two possible reasons for catalyst deactivation: (i) carbon deposition, which can directly block the active sites and/or occlude catalyst mesopores resulting in the loss of the surface area (and hence the active sites) $[15,16,18]$, and (ii) slow oxidation of the $\mathrm{Mo}_{2} \mathrm{C}$ catalyst to form an oxycarbide and/or oxide phases at the surface or the sub-surface upon exposure to the oxygen-containing reactant. A cause of catalyst deactivation is the formation of carbonaceous species occurred during high temperature cycles because no sign of catalyst deactivation was found for another independent catalyst stability test at $420 \mathrm{~K}$ for more than $15 \mathrm{~h}$. (Fig. S3(a), SI), however, oxidation of the carbidic surface at higher reaction temperatures cannot be excluded. Our research does not distinguish between these deactivation mechanisms and instead focuses on understanding the kinetics, mechanism, and site requirements of vapor phase anisole HDO.

An independent kinetic study was conducted to assess the structural evolution of $\mathrm{Mo}_{2} \mathrm{C}$ formulations during anisole HDO. Steady state rates of anisole HDO were 
measured on a $\mathrm{Mo}_{2} \mathrm{C}$ catalyst (sample \#9 in Table 1) at $\sim 420 \mathrm{~K}$ and ambient pressure (Fig. S3(b), SI). The catalyst was then cooled down to RT in flowing $\mathrm{He}\left(\sim 3.33 \mathrm{~cm}^{3} \mathrm{~s}^{-1}\right)$; subsequently treated in a flowing $1 \% \mathrm{O}_{2} / \mathrm{He}$ mixture $\left(\sim 3-4 \mathrm{~cm}^{3} \mathrm{~s}^{-1}\right)$ for $1 \mathrm{~h}$ prior to XRD analysis. The catalyst bed temperature increased from RT to $\sim 333 \mathrm{~K}$ upon exposure to the $1 \% \mathrm{O}_{2} / \mathrm{He}$ mixture suggesting that the catalyst, after exposure to the reactant mixture, was pyrophoric in nature. No noticeable change was observed in the XRD pattern for the spent $\mathrm{Mo}_{2} \mathrm{C}$ catalysts (Fig S2(b),SI), suggesting the bulk structure of the catalyst remained in carbidic form after the HDO reaction.

Benzene selectivity was found to be $>90 \%$ based on $\mathrm{C}_{6}{ }^{+}$products over anisole chemical conversions ranging from $10-100 \%$ for the $\mathrm{Mo}_{2} \mathrm{C}$ formulations we report, which contrasts with the low selectivity $(<50 \%)$ to deoxygenated aromatics (i.e., benzene) obtained using commercial hydrotreating (Co-Mo based) [18, 22, 23], Pt-based [12, 15, 21], transition metal phosphide $\left(\mathrm{Ni}_{2} \mathrm{P}, \mathrm{MoP}\right.$, and $\left.\mathrm{NiMoP}\right)$ [17], or copper chromite [16] catalysts at high hydrogen pressures (1-5 MPa) and high temperatures (523-673 K), but is comparable to the performance of bimetalic FeMo phosphides (FeMoP) catalysts for liquid phase anisole HDO reaction reported by Hicks and coworkers [19]. While the overall selectivity to deoxygenated products for vapor phase anisole HDO reaction was found to be similar (>90\%) between the $\mathrm{Mo}_{2} \mathrm{C}$ catalysts reported here and the $\mathrm{MoO}_{3}$ catalysts reported by Roman-Leshkov and coworkers [27], negligible transalkylation activity was observed for the $\mathrm{Mo}_{2} \mathrm{C}$ catalysts with the sum of the selectivity to toluene and styrene being less than $2 \%$ at all anisole conversions. 
No $\mathrm{C}_{2}-\mathrm{C}_{5}$ products were observed at all reaction temperatures, suggesting that $\mathrm{Mo}_{2} \mathrm{C}$ catalysts are very selective in cleaving $\mathrm{C}-\mathrm{O}$ bonds instead of $\mathrm{C}-\mathrm{C}$ bonds. The ratio of the sum of $\mathrm{C}_{1}$ synthesis rates (methanol + methane, denoted as $\mathrm{C}_{1}$ rates) to the sum of $\mathrm{C}_{6}$ synthesis rates (benzene + cyclohexane, denoted as $\mathrm{C}_{6}$ rates) for the data shown in Figure 4 was found to be near 1 (Figure $S 5$ in the SI), suggesting that $C_{1}$ species are formed in hydrogenolysis reactions of the $\mathrm{Ar}-\mathrm{OCH}_{3}$ bond in anisole, rather than dissociation of $\mathrm{C}_{6}{ }^{+}$products. $\mathrm{C}_{1}$ species are therefore, not included in the $\mathrm{C}_{6}{ }^{+}$selectivity calculation.

Low cyclohexane selectivity ( $<9 \%$; no cyclohexene was observed) showed that vapor phase anisole $\mathrm{HDO}$ on $\mathrm{Mo}_{2} \mathrm{C}$ catalysts is hydrogen efficient. The observed decreasing cyclohexane selectivity as the reaction temperature increased, however, was not thermodynamically, but kinetically controlled because the calculated approach to equilibrium $\left(\eta\right.$, defined as $\left[\mathrm{P}_{\text {cyclohexane }}\right] /\left(\left[\mathrm{P}_{\text {benzene }}\right] \times\left[\mathrm{P}_{\mathrm{H} 2}\right]^{3} \times \mathrm{K}_{\mathrm{eq}}\right.$; where $\mathrm{K}_{\mathrm{eq}}$ is the equilibrium constant for benzene-cyclohexane interconversion) was found to be much smaller than 1.

Two possible explanations for the observed low selectivity to cyclohexane during vapor phase anisole HDO reaction are: (i) the coverage of benzene decreases as the reaction temperature increases, resulting in lower probability of the sequential hydrogenation reaction, and (ii) the surface of $\mathrm{Mo}_{2} \mathrm{C}$ catalysts is influenced by the presence of oxygen when using an oxygenate as a reactant. $\mathrm{Mo}_{2} \mathrm{C}$ catalysts have comparable or even higher turnover rates compared to $\mathrm{Ru}$ catalysts for benzene 
hydrogenation at near ambient temperatures and pressures $[34,39,40]$. A passivated $\mathrm{Mo}_{2} \mathrm{C}$ sample, however, was found to be completely inactive for benzene hydrogenation by Djéga-Mariadassou and coworkers [34]. Figure 5 shows benzene hydrogenation on $\mathrm{Mo}_{2} \mathrm{C}$ catalysts before and after vapor phase anisole HDO reaction at atmospheric pressure. The cyclohexane specific rate was significantly suppressed in the presence of the anisole, suggesting that the presence of oxygen altered the hydrogenation functionality of the $\mathrm{Mo}_{2} \mathrm{C}$ catalysts. Similar suppression in the benzene hydrogenation activity was observed when replacing anisole with methanol or water (Fig. S4, SI). This experimental observation is consistent with the inhibitive relationship between the benzene hydrogenation turnover rate and the residual oxygen content of the $\mathrm{Mo}_{2} \mathrm{C}$ catalysts reported by Djéga-Mariadassou and coworkers [34]. We propose that the remarkably high hydrogen efficiency of $\mathrm{Mo}_{2} \mathrm{C}$ catalysts in anisole $\mathrm{HDO}$ is therefore a consequence of the presence of oxygen-containing species from the reactants, which significantly changes the hydrogenation functionality of $\mathrm{Mo}_{2} \mathrm{C}$ catalysts. Along the same lines, different selectivities (decomposition vs. dehydrogenation) have been reported for cyclohexene reactions on $\mathrm{C} / \mathrm{W}(110)$ pretreated with $\mathrm{O}_{2}$ at different temperatures, suggesting the possibility of manipulating the catalytic selectivity of transition metal carbides by exposure to oxygen [41].

Methane selectivity increased at the expense of methanol selectivity as the reaction temperature and anisole conversion increased (Figure 4(c) and Figure 6), suggesting that the phenolic C-O bond ( $\left.422 \mathrm{~kJ} \mathrm{~mole}^{-1}\right)$ was cleaved first to form methanol and benzene as the primary products and methanol was subsequently hydrodeoxygenated to form 
methane and water. This contrasts with the high selectivity to phenol and the lack of methanol production during anisole HDO over CoMo-based [22, 23], transition metal sulfide [17, 19], and Pt-based catalysts [21], wherein the weaker aliphatic C-O bond $\left(\sim 339 \mathrm{~kJ} \mathrm{~mole}^{-1}\right)$ was preferentially cleaved. The occurrence of demethoxylation, instead of demethylation, for vapor phase anisole $\mathrm{HDO}$ on $\mathrm{Mo}_{2} \mathrm{C}$ was further supported by the very low selectivity to phenol, <1\%, at all anisole conversions (0.6-100\%).

Benzene synthesis rate (mole $\mathrm{s}^{-1} \mathrm{~g}_{\mathrm{Cat}}^{-1}$ ) was independent of anisole chemical conversion (0.6-14\%) achieved using different amount of catalysts (sample \#8 in Table 1, 0.03-0.14 g) as shown in Figure S6 in the SI. This experimental result shows there is no product inhibition and/or the effects of product concentration gradients on the benzene synthesis rate can be neglected at the current reaction conditions.

Figure 7(a) shows that the rate of benzene synthesis does not depend on anisole pressure $(0.06-1.1 \mathrm{kPa})$, indicating the surface is predominantly covered by anisolederived intermediates. The concurrent near half order ( 0.6) dependence of benzene synthesis rates on $\mathrm{H}_{2}$ pressure (Fig. $7(\mathrm{a})$ ) at constant anisole pressure $(\sim 0.14 \mathrm{kPa})$ suggests that dissociative adsorption of hydrogen occurs, however, on sites that are distinct from those required for anisole adsorption because if competition between anisole and molecular hydrogen existed for the same site, we would observe inhibition of catalytic rates by anisole. The hydrogen order was also found to be independent of the anisole concentration $(0.12-0.96 \mathrm{kPa})$ as shown in Fig. 7(b), confirming that distinct sites are required for hydrogen and anisole activation. 
It was suggested by Ko and coworkers that $\mathrm{CO}$ can molecularly chemisorb on exposed on-top sites of Mo on a carbided $\mathrm{Mo}(100)$ surface, while dissociative $\mathrm{H}_{2}$ chemisorption can occur across four-fold hollow sites of the carbide surfaces [42]. These surface science studies are consistent with positive reaction orders for both $\mathrm{H}_{2}$ and $\mathrm{CO}$ in $\mathrm{CO}$ hydrogenation reactions, suggesting that $\mathrm{CO}$ adsorption does not inhibit $\mathrm{H}_{2}$ chemisorption [43]. Similarly, we postulate anisole adsorption can occur on sites resembling those required for $\mathrm{CO}$ chemisorption $\mathrm{CO}$ chemisorption sites are involved in vapor anisole HDO as we discuss in section 3.3), while another type of site, such as fourfold hollow sites, may be responsible for $\mathrm{H}_{2}$ activation.

The apparent activation energy was found to be $\sim 76 \pm 1.3 \mathrm{~kJ} \mathrm{~mole}^{-1}$ (Fig. S7, SI). Figures 8(a) and (b) show that both the hydrogen order and the apparent activation energy were invariant with anisole conversion ( 0.6-15\%, achieved by varying catalyst weight over a range of 0.03-0.14 g), which confirms that the products of anisole HDO do not have measurable kinetic effects on the benzene synthesis rate under these reaction conditions.

A plausible reaction mechanism involving the addition of dissociated hydrogen to adsorbed anisole is proposed to account for the experimentally observed reaction order dependencies: zero order for anisole, $\sim 1 / 2$ order for hydrogen and no kinetic effects of anisole HDO products on the benzene synthesis rate. Hydrogen molecules undergo dissociative adsorption on site $1\left(\mathrm{~S}_{1}\right)$ while anisole molecules $\left(\mathrm{R}\right.$ represents a $\mathrm{C}_{6} \mathrm{H}_{5}$ functional group) adsorb on a distinct site $2\left(\mathrm{~S}_{2}\right)$ [Eq. (1) and (2)]. The dissociated 
hydrogen first binds to the oxygen atom of the adsorbed anisole to give an anisolederived intermediate [Eq. (3)] that facilitates the cleavage of the phenolic C-O bond, presumably because of the strong interaction between the carbidic surface [44-46] and the benzene ring, to generate methanol [Eq. (4)], followed by a sequential addition of dissociated hydrogen to form benzene adsorbed on $S_{2}$ [Eq. (5)]. The adsorbed benzene can then desorb [Eq. (6)] to complete the catalytic cycle.

$$
\begin{aligned}
& \mathrm{H}_{2}+2 \mathrm{~S}_{1} \leftrightarrow 2 \mathrm{H}-\mathrm{S}_{1} \\
& \mathrm{R}-\mathrm{O}-\mathrm{CH}_{3}+\mathrm{S}_{2} \leftrightarrow \mathrm{R}-\mathrm{O}-\mathrm{CH}_{3}-\mathrm{S}_{2} \\
& \mathrm{R}-\mathrm{O}-\mathrm{CH}_{3}-\mathrm{S}_{2}+\mathrm{H}-\mathrm{S}_{1} \leftrightarrow \mathrm{R}-\mathrm{OH}-\mathrm{CH}_{3}-\mathrm{S}_{2}+\mathrm{S}_{1} \\
& \mathrm{R}-\mathrm{OH}-\mathrm{CH}_{3}-\mathrm{S}_{2} \rightarrow \mathrm{R}-\mathrm{S}_{2}+\mathrm{CH}_{3} \mathrm{OH} \\
& \mathrm{R}-\mathrm{S}_{2}+\mathrm{H}-\mathrm{S}_{1} \leftrightarrow \mathrm{R}-\mathrm{H}-\mathrm{S}_{2}+\mathrm{S}_{1} \\
& \mathrm{R}-\mathrm{H}-\mathrm{S}_{2} \leftrightarrow \mathrm{R}-\mathrm{H}+\mathrm{S}_{2}
\end{aligned}
$$

Based on the assumption that (1) cleavage of the strong phenolic $\mathrm{C}-\mathrm{O}$ bond is the rate determining step [Eq. (4)], (2) all other steps are at quasi-equilibrium, and (3) the most abundant reactive intermediate (MARI) for site $2\left(\mathrm{~S}_{2}\right)$ is anisole $\left(\mathrm{R}-\mathrm{O}-\mathrm{CH}_{3}-\mathrm{S}_{2}\right)$ and site $1\left(\mathrm{~S}_{1}\right)$ is predominantly empty, a rate equation for benzene synthesis consistent with the experimentally observed zero order dependence in anisole and half order dependence in $\mathrm{H}_{2}$ can be derived.

Density functional theory (DFT) calculations by Ren et al. have suggested that addition of dissociated hydrogen to an adsorbed propanal molecule on $\mathrm{Mo}_{2} \mathrm{C}$ catalysts 
occurs with an energy barrier exceeding $1 \mathrm{eV}$, which is similar to the step shown in [Eq. (3)]. If we consider this step [Eq. (3)] to be the rate determining step, MARI for site 1 $\left(\mathrm{S}_{1}\right)$ is empty sites, and the coverage of the adsorbed anisole $\left(\mathrm{R}-\mathrm{O}-\mathrm{CH}_{3}-\mathrm{S}_{2}\right)$ species to be much higher than that for all other adsorbates on $S_{2}$ sites, a rate equation for benzene synthesis that can account for experimentally observed zero order in anisole and half order in $\mathrm{H}_{2}$ can also be derived.

Alternatively, considering that oxygen can bind strongly to the surface of $\mathrm{Mo}_{2} \mathrm{C}$ catalysts $[28,47,48]$, the cleavage of the phenolic C-O bond in surface-bound anisole might be facilitated by an adjacent empty site [Eq. (7)], instead of reacting with dissociated hydrogen to form the active intermediate (R-OH-CH $3-\mathrm{S}_{2}$, [Eq. (4)]).

$$
\mathrm{R}-\mathrm{O}-\mathrm{CH}_{3}-\mathrm{S}_{2}+\mathrm{S}_{2} \rightarrow \mathrm{R}-\mathrm{S}_{2}+\mathrm{CH}_{3} \mathrm{O}-\mathrm{S}_{2}
$$

Based on the assumptions that (1) the addition of dissociated hydrogen to the benzene ring intermediate adsorbed on $S_{2}\left(R-S_{2}\right)$ is the rate determining step [Eq. (5)], (2) adsorbed anisole $\left(\mathrm{R}-\mathrm{O}-\mathrm{CH}_{3}-\mathrm{S}_{2}\right)$ and empty sites are the MARI for $\mathrm{S}_{2}$ and $\mathrm{S}_{1}$ respectively, the same benzene synthesis rate dependencies with zero order in anisole and $\sim 1 / 2$ order in $\mathrm{H}_{2}$ can be derived.

The rate equations for benzene synthesis derived from the proposed mechanisms described above can give zero order in anisole and half order in $\mathrm{H}_{2}$. If we consider that (i) there are two types of sites involved in this reaction, one $\left(\mathrm{S}_{1}\right)$ for $\mathrm{H}_{2}$ dissociation and 
the other $\left(\mathrm{S}_{2}\right)$ for anisole activation [Eqs. (1) and (2)], (ii) a non-uniform surface of $\mathrm{S}_{1}$ sites and a uniform surface of $\mathrm{S}_{2}$ sites, and (iii) considering step [Eq. (3)] to be the rate determining step, the fractional order of 0.6 in $\mathrm{H}_{2}$ can be derived, as briefly shown below (A detailed derivation can be found in section 2 in the SI):

We consider [j] such ensembles for the sites $S_{1}$ and the concentration of the dissociatively adsorbed hydrogen in ensemble $\mathrm{j}$ can be derived from site balance in ensemble $\mathrm{j}$ and the equilibrium of [Eq. (1)]:

$$
\left[\mathrm{H}-\mathrm{S}_{1}\right]_{\mathrm{j}}=\left(\frac{\mathrm{k}_{1}}{\mathrm{k}_{-1}}\right)^{\frac{1}{2}}\left[\mathrm{H}_{2}\right]^{\frac{1}{2}} \frac{\left[\mathrm{L}_{1}\right]_{\mathrm{j}}}{1+\left[\mathrm{H}_{2}\right]^{\frac{1}{2}}\left(\frac{\mathrm{k}_{1}}{\mathrm{k}_{-1}}\right)^{\frac{1}{2}}}
$$

The turnover rate, $v_{j, t}$, in each ensemble $\mathrm{j}$ for benzene synthesis can be expressed as

$$
\mathrm{V}_{\mathrm{j}, \mathrm{t}}=\frac{\mathrm{k}_{\mathrm{3}} \mathrm{k}_{1}^{\frac{1}{2}}\left[\mathrm{R}-\mathrm{O}-\mathrm{CH}_{\mathrm{a}}-\mathrm{S}_{2}\right]\left[\mathrm{H}_{2}\right]^{\frac{1}{2}}}{\mathrm{k}_{-1}^{\frac{1}{2}}+\mathrm{k}_{1}^{\frac{1}{2}}\left[\mathrm{H}_{2}\right]^{\frac{1}{2}}}
$$

According to Boudart and Djega-Mariadassou [49], the rate constants can be related to an equilibrium constant and can be expressed as

$$
\begin{aligned}
& \mathrm{k}_{1}=\mathrm{k}_{1}^{\circ} \exp \left(\alpha\left(\mathrm{t}-\mathrm{t}_{0}\right)\right) \\
& \mathrm{k}_{3}=\mathrm{k}_{3}^{\circ} \exp \left((\alpha-1)\left(\mathrm{t}-\mathrm{t}_{0}\right)\right)
\end{aligned}
$$


$\mathrm{k}_{-1}=\mathrm{k}_{-1}^{\circ} \exp \left((\alpha-1)\left(\mathrm{t}-\mathrm{t}_{0}\right)\right)$

where $k_{1}^{\circ}, k_{-1}^{\circ}$, and $k_{3}^{\circ}$ are rate constants in the limit of full coverage; $\alpha$ is a so-called transfer coefficient, which correlates the forward and reverse rate constant of an elementary step to its equilibrium constant; $t$ is dimensionless affinity defined as positive in the direction of adsorption in which $t=\frac{A^{0}}{R T}$ and $t_{0}, t_{1}$ represent the upper bound and lower bound respectively.

An average turnover rate, $v_{t}$, can be obtained by integrating the rates on each ensemble over the entire surface:

$v_{t}=\frac{1}{L_{1}} \int_{t_{1}}^{t_{0}} v_{j, t} \mathrm{dL}_{\mathrm{j}}^{o}$

A continuous site distribution is assumed [49] with the form:

$$
\mathrm{dL}_{\mathrm{j}}^{*}=\frac{\left[\mathrm{L}_{1}\right] \gamma}{\exp (\gamma \mathrm{f})-1} \times \exp \left(-\gamma\left(\mathrm{t}-\mathrm{t}_{0}\right)\right) \mathrm{dt}
$$

where $Y$ is a constant characterizing the site distribution and $\mathrm{dL}_{\mathrm{j}}^{\infty}$ is the concentration of sites with a standard affinity for adsorption of dissociated hydrogen between $A^{\circ}$ and $A^{\circ}+d A^{\circ}$ in the ensemble $\mathrm{j}$ and $\mathrm{f}=\mathrm{t}_{0}-\mathrm{t}_{1}$.

The integrated solution is (the detailed integration procedure can be found in the section 2 in the SI): 


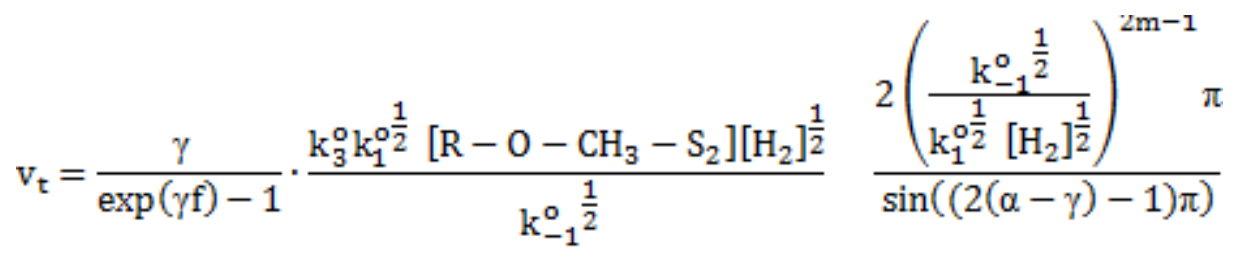

where $\mathrm{m}=\alpha-\gamma$

Therefore, $\quad v_{t} \propto\left[\mathrm{R}-0-\mathrm{CH}_{3}-\mathrm{S}_{2}\right]\left[\mathrm{H}_{2}\right]^{1-m}$

The $S_{2}$ sites would then be treated with uniform surface kinetics and if we assume the MARI on $S_{2}$ is adsorbed anisole species, the order in anisole would be zero and a fractional order of 0.6 for $\mathrm{H}_{2}$ can be obtained with $\mathrm{m}=0.4$.

\subsection{Site requirements of molybdenum carbide catalysts for vapor phase anisole HDO}

The existence of basic, acidic, and metallic catalytic sites on $\mathrm{Mo}_{2} \mathrm{C}$ catalysts has been noted in temperature programmed desorption measurements of probe molecules such as $\mathrm{NH}_{3}, \mathrm{CO}_{2}$, and $\mathrm{CO}$, together with probe reaction studies $[34,35,50]$. The involvement of metallic sites in vapor phase anisole HDO reaction was demonstrated by the near invariance in the turnover rate (TOR) of catalytic hydrodeoxygenation at $420 \mathrm{~K}$ (average value between 1-2 $\mathrm{h}$ time-on-stream) normalized by the number of catalytic centers measured by CO chemisorption (ex situ measurement using Micromeritics 2020) at 323 $\mathrm{K}$ as shown in Table 2. This is also observed for the sample (\#9 in Table 2) prepared by re-carburization of a mixture of multiple batches of $\mathrm{Mo}_{2} \mathrm{C}$ catalysts, which reinforces the idea that the number of $\mathrm{CO}$ chemisorption sites is a relevant descriptor to assess the number of catalytic centers involved in the vapor phase $\mathrm{HDO}$ of anisole on $\mathrm{Mo}_{2} \mathrm{C}$. 
Furthermore, the presence of the species that give a diffraction peak at $\sim 26^{\circ}(2 \theta)$ has no measurable effects on HDO catalytic rates or selectivity as the normalized benzene synthesis rate (mole $\mathrm{s}^{-1}$ mole co site ${ }^{-1}$ ) and benzene selectivity for sample \#8 (with the

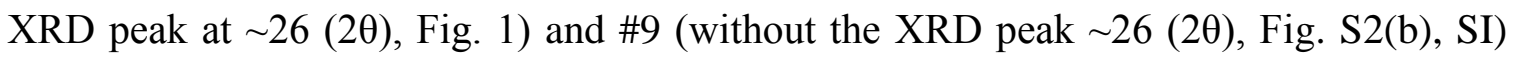
were almost identical $\left(\sim 3 \times 10^{-4}\right.$ mole s$^{-1}$ mole $\mathrm{CO} \operatorname{site}^{-1}$ and $\sim 91 \%$, respectively). The near invariance in measured apparent activation energies $\left(\sim 70 \mathrm{~kJ}\right.$ mole $\left.{ }^{-1}\right)$ and benzene selectivity ( $\sim 92 \%)$ for samples reported in Table 2 suggests that the identity of the active sites and/or the HDO reaction mechanism are similar on all tabulated $\mathrm{Mo}_{2} \mathrm{C}$ samples. These experimental results also confirm the absence of heat and mass transfer limitations because the benzene synthesis rate normalized per $\mathrm{CO}$ chemisorption site was found to be similar, which satisfies the Koros-Nowak criterion [51].

The existence of multiple active sites on $\mathrm{Mo}_{2} \mathrm{C}$ catalysts was further tested by measuring forward rates of $\mathrm{H} / \mathrm{D}$ exchange and benzene synthesis with and without the presence of a $\mathrm{CO}$ co-feed during vapor phase anisole HDO reactions (Figure 9). The measured forward rates of $\mathrm{H} / \mathrm{D}$ exchange and benzene synthesis for $\mathrm{Mo}_{2} \mathrm{C}$ catalysts (sample \#10 in Table 1) at $406 \mathrm{~K}$ in the absence of $\mathrm{CO}$ were found to be $\sim 3.4$ mole $_{\mathrm{HD}} \mathrm{s}^{-1}$ mole $_{\mathrm{CO} \text { site }}{ }^{-1}$ and $\sim 8.7 \times 10^{-5}$ mole $_{\mathrm{HD}} \mathrm{s}^{-1}$ mole $_{\mathrm{CO}}{ }^{-1}{ }^{-1}$, respectively. The forward rate of $\mathrm{H}_{2^{-}}$ $D_{2}$ exchange for noble metal based catalysts was reported to be $90-500$ mole s$^{-1}$ mole $_{\text {surf }}$ metal $^{-1}$ for $\mathrm{SiO}_{2}$ supported noble metal catalysts by Goel et al. [52]. The much lower forward rates of $\mathrm{H} / \mathrm{D}$ exchange for $\mathrm{Mo}_{2} \mathrm{C}$ catalysts ( 3.4 mole $_{\mathrm{HD}} \mathrm{s}^{-1}$ mole $_{\mathrm{COsite}}{ }^{-1}$ ) compared to those for noble metal based catalysts might be attributed to the presence of 
anisole, an oxygen-containing molecule, which inhibits the surface hydrogenation functionality of $\mathrm{Mo}_{2} \mathrm{C}$ formulations as discussed in section 3.2 and Figure 5.

Figure 9 shows that the extent of inhibition by a CO co-feed $\left(\sim 0.0125\right.$ to $0.125 \mathrm{~cm}^{3} \mathrm{~s}^{-}$ ${ }^{1}$ ) for the forward rates of H/D exchange and benzene synthesis was different. This experimental observation suggests that $\mathrm{CO}$ inhibits benzene synthesis, presumably via blocking the sites responsible for anisole adsorption and/or activation, and that $\mathrm{H}_{2}$ activation likely occurs on a distinct site, since otherwise, the normalized forward rates of H/D exchange would be suppressed to the same extent as the normalized benzene synthesis rates upon the introduction of $\mathrm{CO}$ (see Table S3 in the SI for additional information). The inference of the involvement of distinct catalytic sites for the activation of $\mathrm{H}_{2}$ and oxygen-containing molecules on $\mathrm{Mo}_{2} \mathrm{C}$ catalysts from titration studies is consistent with kinetics studies and proposed mechanisms discussed in section 3.2 above to rationalize the measured concurrent zero order dependence in anisole and near half order dependence in $\mathrm{H}_{2}$ observed experimentally.

It is challenging to compare $\mathrm{Mo}_{2} \mathrm{C}$ formulations we report with other catalysts used for vapor phase anisole HDO because (i) the rates reported are typically at varying conversions [15,19,27], (ii) fast catalyst deactivation is encountered in some cases [28], (iii) product inhibition may become relevant for other catalysts, and (iv) the identity of the active sites is not known. Since benzene is not necessarily the dominant product from anisole HDO reactions, the specific rate for deoxygenation products per gram of catalyst and/or the number of active centers assessed by chemical adsorption experiments is 
compared. Rom an-Leshkov and coworkers reported specific rates for deoxygenation of anisole on $\mathrm{MoO}_{3}$ catalysts to be $\sim 7.5 \times 10^{-6}$ mole s$^{-1} \mathrm{~g}_{\mathrm{Cat}}{ }^{-1}$ with benzene, toluene, xylene and alkylbenzens as major products at $673 \mathrm{~K}$ and $1 \mathrm{~atm}[27]$ and that for a $1 \mathrm{wt} \% \mathrm{Pt} / \mathrm{H}$ -

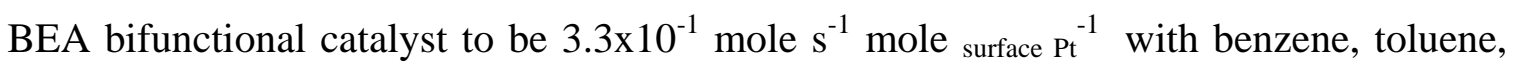
xylene and $\mathrm{C}_{9}{ }^{+}$aromatics as major deoxygenation products at $673 \mathrm{~K}$ at 1atm. [15] Hicks and coworkers reported that $\sim 92 \%$ anisole conversion with deoxygenation product selectivity $\sim 96 \%$ (90\% for benzene and 6\% for cyclohexane) could be achieved by a FeMo bimetallic phosphides catalyst (FeMoP) in $0.5 \mathrm{~h}$ in a liquid phase batch reactor, which corresponds to a specific deoxygenation rate of $\sim 1.7 \times 10^{-3}$ mole s $^{-1}$ mole $_{\text {metal }}{ }^{-1}$ at $673 \mathrm{~K}$ under 4.2 $\mathrm{MPa}_{2}$ [19]. The deoxygenation rate based on the rate of benzene synthesis (excluding cyclohexane) for $\mathrm{Mo}_{2} \mathrm{C}$ formulations $\left(\sim 3 \times 10^{-4}\right.$ at $423 \mathrm{~K}$, Table 2$)$ extrapolated to $673 \mathrm{~K}$ based on the apparent $\mathrm{Ea} \sim 70 \mathrm{~kJ}^{\mathrm{mole}}{ }^{-1}$ (Table 2) and under ambient pressure is $\sim 4.8 \times 10^{-1}$ mole s $^{-1}$ mole Co sites $^{-1}$.

Density functional theory (DFT) calculations by Rodriguez and coworkers have suggested that Mo oxycarbide is formed on the surface of a $\mathrm{Mo}_{2} \mathrm{C}$ catalyst during water gas shift (WGS) and is responsible for the experimentally observed high WGS activity [47]. The authors proposed that chemisorbed oxygen from water dissociation could be destabilized by the C-terminated $\mathrm{Mo}_{2} \mathrm{C}$ (001) surface, which facilitates intermediate strength binding of reaction intermediates and therefore enhances the rate of the WGS reaction. In this work, since the oxygen in anisole can be removed as either water or methanol, depending on anisole chemical conversion, the possibility of in situ formation of oxycarbide phase during vapor phase HDO, therefore, cannot be excluded. We also 
note that the existence or involvement of carbidic or oxycarbidic phases [52] cannot be inferred from the $\mathrm{CO}$ adsorption studies we report above and the identification of working active phase during HDO reaction requires additional characterization. Although the identity of the two active sites involved in vapor phase anisole HDO on $\mathrm{Mo}_{2} \mathrm{C}$ catalysts cannot be inferred from our results, we report that $\mathrm{Mo}_{2} \mathrm{C}$ is a stable and selective catalyst for deoxygenation of aromatic ethers at ambient pressures and low temperatures for the synthesis of aromatics and report kinetic and chemical titration studies to infer the involvement of (i) two distinct sites in this chemistry, and (ii) metallic sites in this chemistry that can be titrated by $\mathrm{CO}$ to rigorously calculate catalytic rates. 


\section{Conclusions}

In summary, molybdenum carbide catalysts can convert anisole to benzene in the vapor phase with unprecedented selectivity (>90\% among $\mathrm{C}_{6}{ }^{+}$products), high hydrogen efficiency, ( $<9 \%$ selectivity for the undesired sequential hydrogenation product, cyclohexane) and stable rates at low reaction temperatures (420-520K) and ambient pressure. The stronger phenolic $\mathrm{C}-\mathrm{O}$ bond, instead of the weaker aliphatic $\mathrm{C}-\mathrm{O}$ bond ( $\sim 22$ vs. $\left.\sim 339 \mathrm{~kJ} \mathrm{~mole}^{-1}\right)$ in anisole was preferentially cleaved during the HDO reaction. The products of anisole HDO showed no measureable kinetic inhibition effects on the benzene synthesis rate. At least two distinct sites are required and metallic sites are involved in vapor phase anisole $\mathrm{HDO}$ on $\mathrm{Mo}_{2} \mathrm{C}$ catalysts. Benzene synthesis rates were found to inhibited to a greater extent than forward rates of H/D exchange upon co-feeding $\mathrm{CO}$ in the reaction mixture, suggesting that the catalytic sites for $\mathrm{H}_{2}$ activation are distinct from those for anisole adsorption and/or activation. Taken together with the remarkable selectivity for benzene, the relatively low reaction temperature, and low $\mathrm{H}_{2}$ pressure required to break the phenolic $\mathrm{C}-\mathrm{O}$ bond, these initial findings show molybdenum carbide is a promising catalyst for catalytic deoxygenation with particular relevance to ligninderived phenolic ethers. 


\section{Acknowledgments}

This research was supported by Office of Basic Energy Sciences, the U.S. Department of Energy under award number no. DE-SC0008418 (DOE Early Career Program). Part of this work was carried out in the Characterization Facility of the University of Minnesota, which receives partial support from the National Science Foundation through the MRSEC program. We thank Professor Fabio Ribeiro of Purdue University for helpful technical discussions and Mr. Minje Kang for preparing the $\mathrm{Pd} / \mathrm{Al}_{2} \mathrm{O}_{3}$ catalyst used in this research. 


\section{Reference}

[1] H.M. Wang, J. Male, and Y. Wang, ACS Catal. 3 (2013) 1047-1070.

[2] J. Zakzeski, P.C.A. Bruijnincx, A.L. Jongerius, and B.M. Weckhuysen, Chem. Rev. 110 (2010) 3552-3599.

[3] G.W. Huber, and J.A. Dumesic, Catal. Today 111 (2006) 119-132.

[4] R.W. Gosselink, D.R. Stellwagen, and J.H. Bitter, Angew. Chem., Int. Ed. 52 (2013) 5089-5092.

[5] J.Y. He, C. Zhao, and J.A. Lercher, J. Am. Chem. Soc. 134 (2012) 20768-20775.

[6] N. Yan, Y.A. Yuan, R. Dykeman, Y.A. Kou, and P.J. Dyson, Angew. Chem., Int. Ed. 49 (2010) 5549-5553.

[7] C. Zhao, Y. Kou, A.A. Lemonidou, X.B. Li, and J.A. Lercher, Angew. Chem., Int. Ed. 48 (2009) 3987-3990.

[8] D.C. Elliott, Energy Fuels 21 (2007) 1792-1815.

[9] H.Y. Zhao, D. Li, P. Bui, and S.T. Oyama, Appl. Catal., A 391 (2011) 305-310.

[10] A. Centeno, E. Laurent, and B. Delmon, J. Catal. 154 (1995) 288-298.

[11] B. Donnis, R.G. Egeberg, P. Blom, and K.G. Knudsen, Top. Catal. 52 (2009) 229240.

[12] M.A. Gonzalez-Borja, and D.E. Resasco, Energy Fuels 25 (2011) 4155-4162.

[13] D. Meier, J. Berns, O. Faix, U. Balfanz, and W. Baldauf, Biomass Bioenergy 7 (1994) 99-105.

[14] J.Q. Bond, D.M. Alonso, D. Wang, R.M. West, and J.A. Dumesic, Science 327 (2010) 1110-1114.

[15] X.L. Zhu, L.L. Lobban, R.G. Mallinson, and D.E. Resasco, J. Catal. 281 (2011) 21-29.

[16] K.L. Deutsch, and B.H. Shanks, Appl. Catal., A 447 (2012) 144-150.

[17] K.L. Li, R.J. Wang, and J.X. Chen, Energy Fuels 25 (2011) 854-863.

[18] C.V. Loricera, B. Pawelec, A. Infantes-Molina, M.C. Alvarez-Galvan, R. Huirache-Acuna, R. Nava, and J.L.G. Fierro, Catal. Today 172 (2011) 103-110.

[19] D.J. Rensel, S. Rouvimov, M.E. Gin, and J.C. Hicks, J. Catal. 305 (2013) 256263.

[20] R.C. Runnebaum, R.J. Lobo-Lapidus, T. Nimmanwudipong, D.E. Block, and B.C. Gates, Energy Fuels 25 (2011) 4776-4785.

[21] R.C. Runnebaum, T. Nimmanwudipong, D.E. Block, and B.C. Gates, Catal. Lett. 141 (2011) 817-820.

[22] S.J. Hurff, and M.T. Klein, Ind. Eng. Chem. Fundam. 22 (1983) 426-430.

[23] A.L. Jongerius, R. Jastrzebski, P.C.A. Bruijnincx, and B.M. Weckhuysen, J. Catal. 285 (2012) 315-323.

[24] S.T. Oyama, T. Gott, H.Y. Zhao, and Y.K. Lee, Catal. Today 143 (2009) 94-107.

[25] S.T. Oyama, X. Wang, F.G. Requejo, T. Sato, and Y. Yoshimura, J. Catal. 209 (2002) 1-5.

[26] Y.Y. Shu, and S.T. Oyama, Chem. Commun. (2005) 1143-1145.

[27] T. Prasomsri, T. Nimmanwudipong, and Y. Roman-Leshkov, Energy Environ. Sci. 6 (2013) 1732-1738. 
[28] H. Ren, W. Yu, M. Salciccioli, Y. Chen, Y. Huang, K. Xiong, D.G. Vlachos, and J.G.G. Chen, ChemSusChem 6 (2013) 798-801.

[29] W.T. Yu, Z.J. Mellinger, M.A. Barteau, and J.G.G. Chen, J. Phys. Chem. C 116 (2012) 5720-5729.

[30] J.X. Han, J.Z. Duan, P. Chen, H. Lou, X.M. Zheng, and H.P. Hong, ChemSusChem 5 (2012) 727-733.

[31] A.L. Jongerius, R.W. Gosselink, J. Dijkstra, J.H. Bitter, P.C.A. Bruijnincx, and B.M. Weckhuysen, ChemCatchem 5 (2013) 2964-2972.

[32] J.A. Schaidle, A.C. Lausche, and L.T. Thompson, J. Catal. 272 (2010) 235-245.

[33] J. Patt, D.J. Moon, C. Phillips, and L.T. Thompson, Catal. Lett. 65 (2000) 193195.

[34] J.S. Choi, G. Bugli, and G. Djega-Mariadassou, J. Catal. 193 (2000) 238-247.

[35] J.S. Lee, S.T. Oyama, and M. Boudart, J. Catal. 106 (1987) 125-133.

[36] F.H. Ribeiro, R.A.D. Betta, G.J. Guskey, and M. Boudart, Chem. Mater. 3 (1991) 805-812.

[37] G.S. Ranhotra, G.W. Haddix, A.T. Bell, and J.A. Reimer, J. Catal. 108 (1987) 2439.

[38] E.A. Blekkan, P.H. Cuong, M.J. Ledoux, and J. Guille, Ind. Eng. Chem. Res. 33 (1994) 1657-1664.

[39] J.S. Lee, M.H. Yeom, K.Y. Park, I.S. Nam, J.S. Chung, Y.G. Kim, and S.H. Moon, J. Catal. 128 (1991) 126-136.

[40] C. MarquezAlvarez, J.B. Claridge, A.P.E. York, J. Sloan, and M.L.H. Green, Stud. Surf. Sci. Catal. (1997) 485-490.

[41] N. Liu, S.A. Rykov, and J.G. Chen, Surf. Sci. 487 (2001) 107-117.

[42] E.I. Ko, and R.J. Madix, Surf. Sci. 100 (1980) L449-L453.

[43] G.S. Ranhotra, A.T. Bell, and J.A. Reimer, J. Catal. 108 (1987) 40-49.

[44] X.C. Liu, A. Tkalych, B.J. Zhou, A.M. Koster, and D.R. Salahub, J. Phys. Chem. C 117 (2013) 7069-7080.

[45] A.S. Rocha, A.B. Rocha, and V.T. da Silva, Appl. Catal., A 379 (2010) 54-60.

[46] B.J. Zhou, X.C. Liu, J. Cuervo, and D.R. Salahub, Struct. Chem. 23 (2012) 14591466.

[47] P. Liu, and J.A. Rodriguez, J. Phys. Chem. B 110 (2006) 19418-19425.

[48] A.J. Medford, A. Vojvodic, F. Studt, F. Abild-Pedersen, and J.K. Norskov, J.Catal. 290 (2012) 108-117.

[49] M. Boudart, and G. Djéga-Mariadassou, Kinetics of Heterogeneous Catalytic Reactions Princeton University Press, Princeton, 1984.

[50] S.K. Bej, and L.T. Thompson, Appl. Catal., A 264 (2004) 141-150.

[51] S. Koso, Y. Nakagawa, and K. Tomishige, J. Catal. 280 (1967) 221-229.

[52] S. Goel, Z.J. Wu, S.I. Zones, and E. Iglesia, J. Am. Chem. Soc. 134 (2012) 17688-17695.

[53] H.H. Hwu, M.B. Zellner, and J.G.G. Chen, J. Catal. 229 (2005) 30-44. 
Table 1. Preparation conditions for high surface area $\mathrm{Mo}_{2} \mathrm{C}$ samples with varying numbers of catalytic centers measured by $\mathrm{CO}$ chemisorption at $323 \mathrm{~K}$.

\begin{tabular}{|c|c|c|c|c|c|}
\hline Catalysts & $\begin{array}{c}\mathrm{AMT}^{\mathrm{a}} \\
(\mathrm{g})\end{array}$ & $\begin{array}{l}\mathrm{CH}_{4} \text { flow } \\
\text { rate } \\
\left(\mathrm{cm}^{3} \mathrm{~s}^{-1}\right)\end{array}$ & $\begin{array}{l}\mathrm{H}_{2} \text { flow } \\
\text { rate } \\
\left(\mathrm{cm}^{3} \mathrm{~s}^{-1}\right)\end{array}$ & Temp profile ${ }^{c}$ & $\begin{array}{c}\text { CO uptake at } \\
323 \mathrm{~K} \\
\left(\mu \mathrm{mole} \mathrm{g}^{-1},\right. \\
\text { STP })\end{array}$ \\
\hline$\# 1$ & 3.0 & 0.44 & 0.65 & $\mathrm{CH}_{4} / \mathrm{H}_{2}-\mathrm{RT}(1.5 \mathrm{~h})-623 \mathrm{~K}[24 \mathrm{~h}](1.5 \mathrm{~h})-873 \mathrm{~K}[6 \mathrm{~h}]-\mathrm{cool}$ & 51 \\
\hline \#2 & 6.0 & 0.44 & 2.49 & $\mathrm{CH}_{4} / \mathrm{H}_{2}-\mathrm{RT}(1.5 \mathrm{~h})-623 \mathrm{~K}[12 \mathrm{~h}](1.5 \mathrm{~h})-978 \mathrm{~K}[3 \mathrm{~h}]-\mathrm{cool}$ & 92 \\
\hline \#3 & 2.4 & 0.44 & 2.49 & $\mathrm{H}_{2}-\mathrm{RT}(1.5 \mathrm{~h})-618 \mathrm{~K}[15 \mathrm{~h}]-\mathrm{CH}_{4} / \mathrm{H}_{2}(1.5 \mathrm{~h})-863 \mathrm{~K}[2 \mathrm{~h}]-\mathrm{cool}$ & 101 \\
\hline \#4 & 6.0 & 0.44 & 2.49 & $\mathrm{H}_{2}-\mathrm{RT}(1.5 \mathrm{~h})-618 \mathrm{~K}[15 \mathrm{~h}]-\mathrm{CH}_{4} / \mathrm{H}_{2}(1.5 \mathrm{~h})-863 \mathrm{~K}[2 \mathrm{~h}] \mathrm{cool}$ & 120 \\
\hline \#5 & 0.6 & 0.44 & 2.49 & $\mathrm{CH}_{4} / \mathrm{H} 2-\mathrm{RT}(1.5 \mathrm{~h})-623 \mathrm{~K}[12 \mathrm{~h}](1.5 \mathrm{~h})-873 \mathrm{~K}[2 \mathrm{~h}]-\mathrm{cool}$ & 122 \\
\hline \#6 & 3.6 & 0.44 & 2.49 & $\mathrm{CH}_{4} / \mathrm{H} 2-\mathrm{RT}(1.5 \mathrm{~h})-623 \mathrm{~K}[12 \mathrm{~h}](1.5 \mathrm{~h})-858 \mathrm{~K}[4 \mathrm{~h}]-\mathrm{cool}$ & 130 \\
\hline \#7 & 0.6 & 0.29 & 1.66 & $\mathrm{H}_{2}-\mathrm{RT}(1.5 \mathrm{~h})-618 \mathrm{~K}[15 \mathrm{~h}]-\mathrm{CH}_{4} / \mathrm{H}_{2}(1.5 \mathrm{~h})-863 \mathrm{~K}[2 \mathrm{~h}]-\mathrm{cool}$ & 163 \\
\hline \#8 & 0.6 & 0.44 & 2.49 & $\mathrm{CH}_{4} / \mathrm{H}_{2}-\mathrm{RT}(1.5 \mathrm{~h})-623 \mathrm{~K}[12 \mathrm{~h}](1.5 \mathrm{~h})-863 \mathrm{~K}[2 \mathrm{~h}]-\mathrm{cool}$ & 220 \\
\hline \#9 & $6.0^{\mathrm{b}}$ & 1.33 & 8.33 & $\mathrm{CH}_{4} / \mathrm{H}_{2}-\mathrm{RT}(1.5 \mathrm{~h})-623 \mathrm{~K}[0 \mathrm{~h}](1.5 \mathrm{~h})-908 \mathrm{~K}[3 \mathrm{~h}]-\mathrm{cool}$ & 152 \\
\hline \#10 & 1.5 & 0.42 & 2.33 & $\mathrm{CH}_{4} / \mathrm{H}_{2}-\mathrm{RT}(1.5 \mathrm{~h})-628 \mathrm{~K}[5 \mathrm{~h}](1.5 \mathrm{~h})-883 \mathrm{~K}[3 \mathrm{~h}]-\mathrm{cool}$ & 208 \\
\hline
\end{tabular}

a: ammonium molybdate tetrahydrate $\left(\left(\mathrm{NH}_{4}\right)_{6} \mathrm{Mo}_{7} \mathrm{O}_{24} \cdot 4 \mathrm{H}_{2} \mathrm{O}\right.$, sieved $\left.177-400 \mu \mathrm{m}\right)$.

b: Samples were prepared by re-carburizing a mixture of multiple batches of $\mathrm{Mo}_{2} \mathrm{C}$ catalysts $(\sim 6 \mathrm{~g})$ with different amounts of CO chemisorption sites using the conditions shown in this table.

c: Detailed description for the preparation conditions can be found in section 2.1. For the catalysts prepared from heating in the pure $\mathrm{H}_{2}$ environments first, such as sample \#3 ( $\mathrm{H}_{2}-$ RT(1.5h)-618K[15h]- $\left.\mathrm{CH}_{4} / \mathrm{H}_{2}(1.5 \mathrm{~h})-863 \mathrm{~K}[2 \mathrm{~h}]-\mathrm{cool}\right)$, the switch of $\mathrm{H}_{2}$ to $\mathrm{CH}_{4} / \mathrm{H}_{2}$ was achieved by adding $\mathrm{CH}_{4}\left(0.44 \mathrm{~cm}^{3} \mathrm{~s}^{-1}\right)$ to the existing $\mathrm{H}_{2}$ flow (2.49 ( $\left.\mathrm{cm}^{3} \mathrm{~s}^{-1}\right)$.

$\mathrm{d}$ : Except for sample \#8 and \#10 in which $\mathrm{CO}$ chemisorption were measured within one day of the $\mathrm{Mo}_{2} \mathrm{C}$ catalyst synthesis, the rest of the samples were stored in vials for a few weeks prior to both $\mathrm{CO}$ chemisorption and the kinetic measurements. The $\mathrm{CO}$ chemisorption and the kinetic measurements were carried out on the same day for each sample listed above. 
Table 2. Catalytic performance (benzene turnover rate (TOR), benzene selectivity and apparent Ea) of vapor phase anisole HDO for high surface area $\mathrm{Mo}_{2} \mathrm{C}$ samples with varying numbers of catalytic centers measured by $\mathrm{CO}$ chemisorption at $323 \mathrm{~K}$.

\begin{tabular}{|c|c|c|c|c|}
\hline Catalysts $^{\mathrm{a}}$ & $\begin{array}{l}\text { CO uptake at } 323 \mathrm{~K} \\
\left(\mu \text { mole } \mathrm{g}^{-1}, \mathrm{STP}\right)^{\mathrm{b}}\end{array}$ & $\begin{array}{c}\text { benzene TOR at } 423 \\
\mathrm{~K}\left(\times 10^{-4} \text { mole s}^{-1}\right. \\
\left.\text { mole }_{\mathrm{CO} \text { site }}{ }^{-1}\right)^{\mathrm{c}}\end{array}$ & $\begin{array}{c}\text { Benzene } \\
\text { selectivity } \\
(\%)^{\mathrm{c}}\end{array}$ & $\begin{array}{c}\text { Apparent } \\
\text { activation energy, } \\
\text { Ea }\left(\mathrm{kJ} \text { mole }^{-1}\right)\end{array}$ \\
\hline$\# 1$ & 51 & 4.2 & 93 & $75.8 \pm 1.8$ \\
\hline$\# 2$ & 92 & 3.1 & 91 & $72.7 \pm 0.8$ \\
\hline$\# 3$ & 101 & 2.7 & 91 & $71.5 \pm 1.3$ \\
\hline$\# 4$ & 120 & 2.9 & 91 & $69.3 \pm 4.5$ \\
\hline$\# 5$ & 122 & 3.0 & 90 & $71.0 \pm 0.4$ \\
\hline \#6 & 130 & 4.3 & 94 & $67.8 \pm 1.8$ \\
\hline$\# 7$ & 163 & 5.7 & 94 & $69.3 \pm 1.8$ \\
\hline$\# 8$ & 220 & $3.0^{\mathrm{d}}$ & 92 & ND \\
\hline$\# 9$ & 152 & $2.7^{\mathrm{d}}$ & 91 & ND \\
\hline$\# 10$ & 208 & $2.6^{\mathrm{e}}$ & 92 & ND \\
\hline
\end{tabular}

a: Detailed preparation conditions for the listed samples can be found in Table 1.

b: Except for sample \#8 and \#10 in which CO chemisorption were measured within one day of the $\mathrm{Mo}_{2} \mathrm{C}$ catalyst synthesis, the rest of the samples were stored in vials for a few weeks prior to both CO chemisorption and the kinetic measurements. The CO chemisorption and the kinetic measurements were carried out on the same day for each sample listed above.

c: The reported rate represents an average value at $423 \mathrm{~K}$ between $1-2 \mathrm{~h}$ time-on-stream with anisole conversion $<14 \%$. Reaction conditions: anisole $/ \mathrm{H}_{2}=\sim 0.14 \% / \mathrm{bal}\left(1.67 \mathrm{~cm}{ }^{3} \mathrm{~s}\right.$ $\left.{ }^{1}\right)$ at $\sim 423 \mathrm{~K}$; catalyst loading: $80-250 \mathrm{mg}$.

d: Reaction temperature was $\sim 420 \mathrm{~K}$. Apparent activation energy $\sim 70 \mathrm{~kJ}^{-1} \mathrm{~mole}^{-1}$ was used to calculate the rate at $423 \mathrm{~K}$ by extrapolation.

ND: not determined

e: The reported rate represents an average value between $1-2 \mathrm{~h}$ time-on-stream with reaction conditions: anisole $/ \mathrm{H}_{2}=\sim 0.14 \% / \mathrm{bal}\left(1.67 \mathrm{~cm}^{3} \mathrm{~s}^{-1}\right)$ at $406 \mathrm{~K}$ prior to $\mathrm{H}_{2}-\mathrm{D}_{2}-\mathrm{CO}$ titration experiment shown in Figure 9 with catalyst loading: $\sim 0.0221 \mathrm{~g}$. Apparent activation energy $\sim 70 \mathrm{~kJ}^{\mathrm{mole}}{ }^{-1}$ was used to calculate the rate at $423 \mathrm{~K}$ by extrapolation.

ND: not determined 


\section{Figure Captions}

Figure 1. X-ray diffraction pattern for the fresh, passivated $\mathrm{Mo}_{2} \mathrm{C}$ catalyst (sample \#8 in Table 1).

Figure 2. $\mathrm{N}_{2}$ adsorption ( $\bullet$ )/desorption ( $\bullet$ ) isotherm at $77 \mathrm{~K}$ for the fresh, passivated $\mathrm{Mo}_{2} \mathrm{C}$ catalyst (sample \#8 in Table 1).

Figure 3. A representative TEM image of the fresh, passivated $\mathrm{Mo}_{2} \mathrm{C}$ catalyst (sample \#8 in Table 1). Lattice fringes (indicated by arrow) corresponding to the (100) plane of $\beta-\mathrm{Mo}_{2} \mathrm{C}$ were identified.

Figure 4. (a) Conversion of anisole (b) measured selectivity for benzene $(\mathrm{O})$, cyclohexane ( $\star$ ) and sum of toluene, styrene and phenol $(\diamond)$ and (c) measured selectivity for methane ( ) and methanol ( ) on $\mathrm{Mo}_{2} \mathrm{C}$ (sample \#8 in Table 1) as a function of temperature and time-on-stream at $1 \mathrm{~atm}$. Reaction conditions: anisole $/ \mathrm{H}_{2}=$ $\sim 0.14 \%$ /bal (total flow rate $\sim 1.67 \mathrm{~cm}^{3} \mathrm{~s}^{-1}$ ), space velocity $\sim 17 \mathrm{~cm}^{3} \mathrm{~s}^{-1} \mathrm{~g}_{\text {cat }}{ }^{-1}$ and catalyst loading 97 mg.

Figure 5. Cyclohexane production rate measured from either benzene hydrogenation reaction ( $\boldsymbol{\square}$, shaded areas) or vapor phase anisole $\mathrm{HDO}$ reaction ( $\square$ ) on a $\mathrm{Mo}_{2} \mathrm{C}$ catalyst. Benzene synthesis rate $(\mathrm{O})$ indicates deoxygenation activity. The catalyst was first tested for benzene hydrogenation for $\sim 10 \mathrm{ks}$ (feed composition: benzene $/ \mathrm{H}_{2}=$ $0.23 \% / \mathrm{bal}$ with total flow rate $\sim 1.67 \mathrm{~cm}^{3} \mathrm{~s}^{-1}$ ) and then switched to vapor phase anisole HDO reaction (feed composition: aniole/ $/ \mathrm{H}_{2}=0.14 \% / \mathrm{bal}$ with total flow rate $\sim 1.67 \mathrm{~cm}^{3}$ $\mathrm{s}^{-1}$ ), followed by restoring the reaction conditions to benzene hydrogenation. The reaction temperature was maintained at $\sim 423 \mathrm{~K}$ under ambient pressure during the switch of aforementioned two different reactions. Catalyst loading was $\sim 150 \mathrm{mg}$. 
Figure 6. Selectivity of methane ( ) and methanol ( ) as a function of anisole conversion; a range of anisole conversion was achieved by using different amounts of catalyst or varying the reaction temperature. Reaction conditions: anisole $/ \mathrm{H}_{2}=$ $\sim 0.14 \%$ /bal (total flow rate $\sim 1.67 \mathrm{~cm}^{3} \mathrm{~s}^{-1}$ ), and catalyst loading $\sim 11$ to $\sim 140 \mathrm{mg}$. The dashed lines drawn are a guide to the eye.

Figure 7. (a) Effect of $\mathrm{H}_{2}$ pressure (( $\left.\boldsymbol{\square}\right)$ varied from $\sim 0.1$ to $\sim 1$ atm (balance $\mathrm{He}$ ) at $\sim 0.14 \mathrm{kPa}$ anisole at $423 \mathrm{~K})$ and anisole pressure $((\Delta)$ varied from $\sim 0.06$ to $\sim 1 \mathrm{kPa}$, balance $\mathrm{H}_{2}$ at $423 \mathrm{~K}$ ) and (b) Hydrogen order measured at different anisole concentrations. Experimental data obtained at $423 \mathrm{~K}$, total pressure $=1 \mathrm{~atm}$.

Figure 8. (a) Hydrogen order and (b) apparent activation energy as a function of anisole conversion. Experimental data obtained at $423 \mathrm{~K}, \mathrm{H}_{2}$ pressure varied from $\sim 0.1$ to $\sim 1 \mathrm{~atm}$ (balance $\mathrm{He}$ ) at $\sim 0.14 \mathrm{kPa}$ anisole, total pressure $=1 \mathrm{~atm}$. Anisole conversion was adjusted by using different amounts of $\mathrm{Mo}_{2} \mathrm{C}$ catalysts $(0.03-0.14 \mathrm{~g})$ with total flow rate $\sim 1.67 \mathrm{~cm}^{3} \mathrm{~s}^{-1}$.

Figure 9. Effects of $\mathrm{CO}$ co-feed during vapor phase anisole hydrodeoxygenation on normalized benzene synthesis $(\cdot \times)$ and H/D exchange forward rates $(\bullet)$. Forward rates of H/D exchange and benzene synthesis rates with a CO co-feed (from 0.0125 to 0.125 $\mathrm{cm}^{3} \mathrm{~s}^{-1}$ ) were normalized to those measured under standard conditions (STD, in the absence of CO co-feed) prior to the CO titration. See Table S3 in the SI for measured rates of H/D isotopic exchange and benzene synthesis. CO was co-fed into the reactant mixture comprising anisole $/ \mathrm{D}_{2} / \mathrm{H}_{2} / \mathrm{Ar}(\mathrm{vol} \%)=\sim 0.12 / 40 / 40 /$ bal with a total flow rate $\sim 1.67 \mathrm{~cm}^{3} \mathrm{~s}^{-1}$ at reaction temperature $\sim 406 \mathrm{~K}$ under ambient pressure; $\mathrm{Mo}_{2} \mathrm{C}$ loading $\sim 0.0221 \mathrm{~g}$ (sample \#10 in Table 1). The dashed lines drawn are a guide to the eye. 
Fig. 1

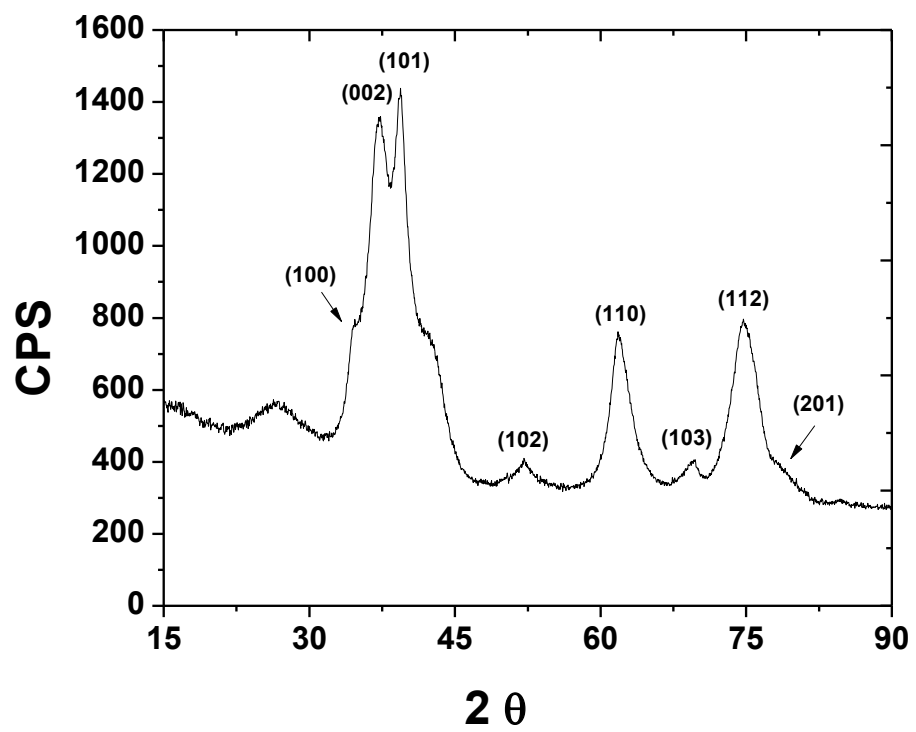

Fig. 2

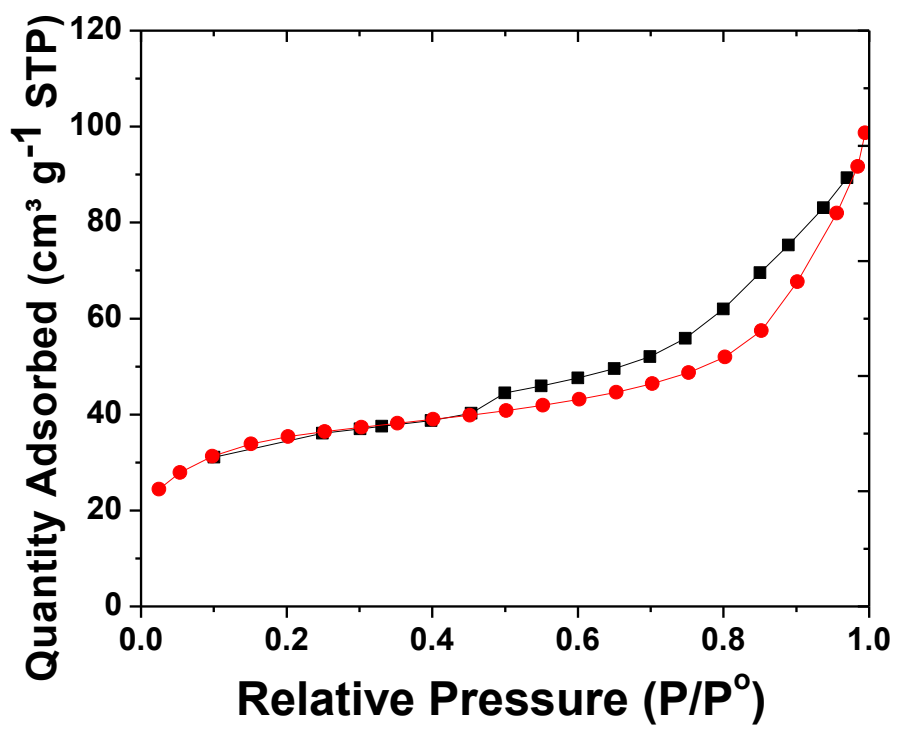


Fig. 3

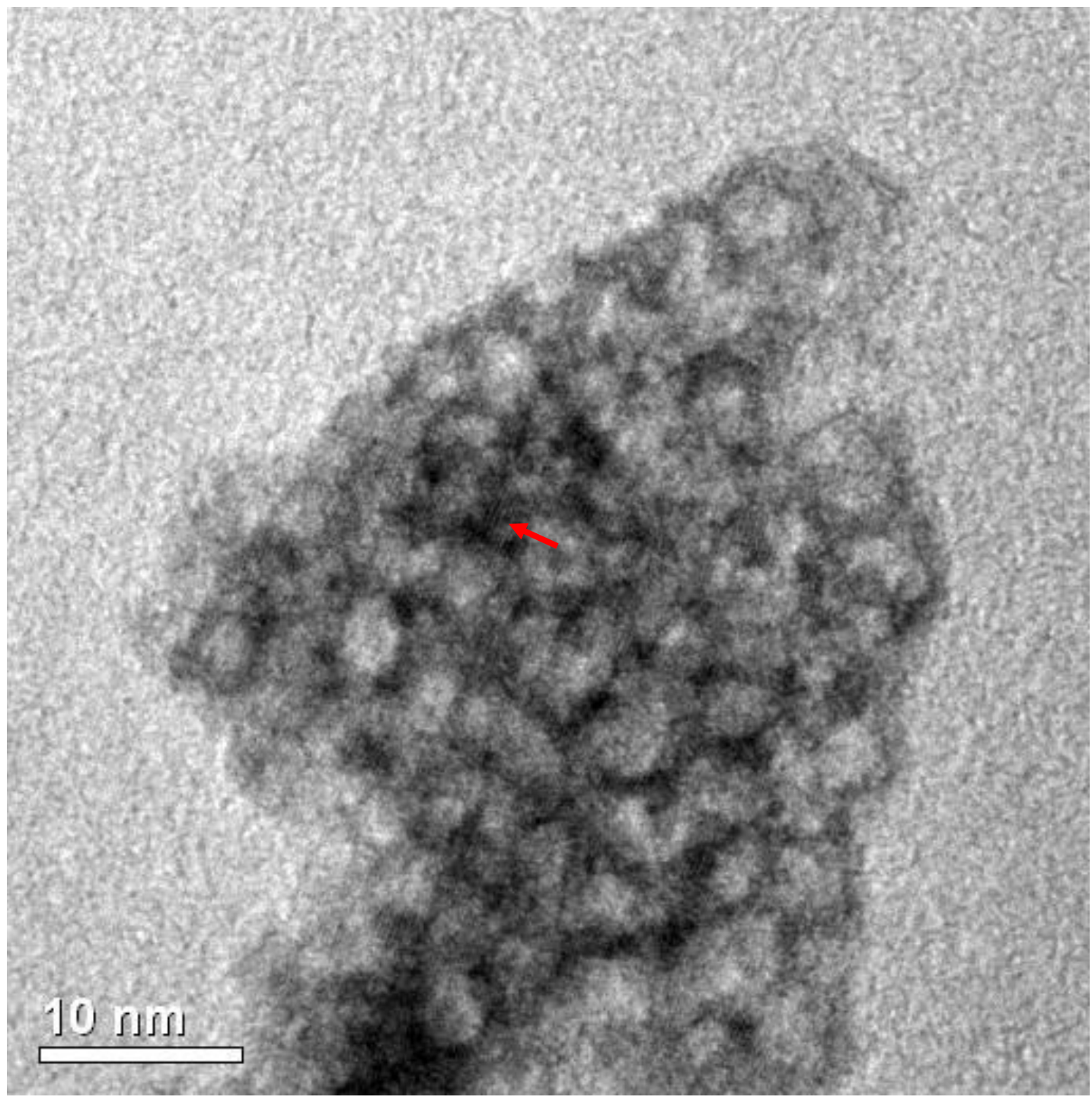


(a)

Fig. 4

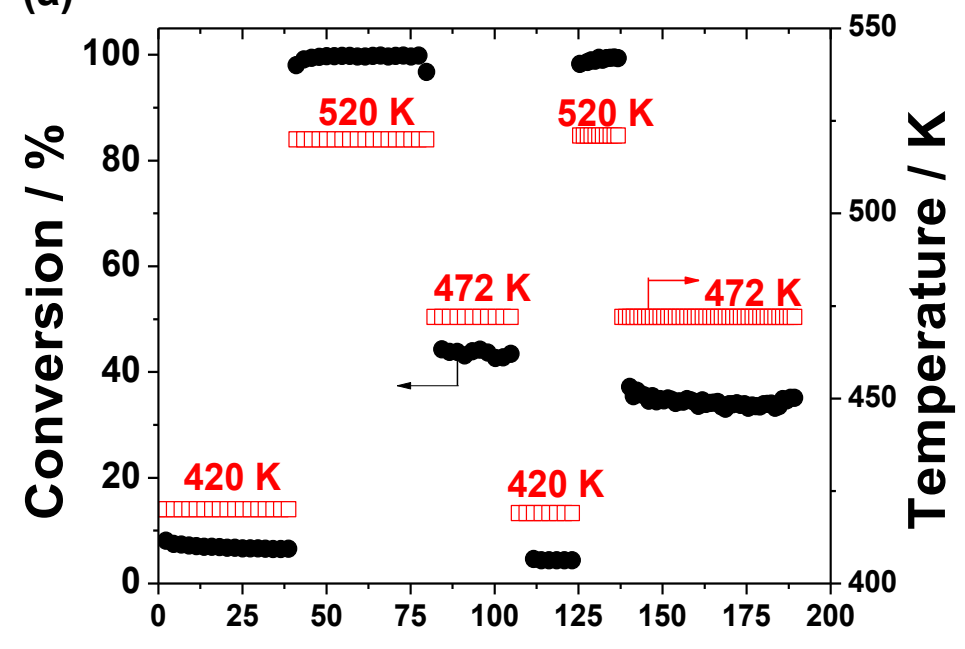

Time / ks

(b)

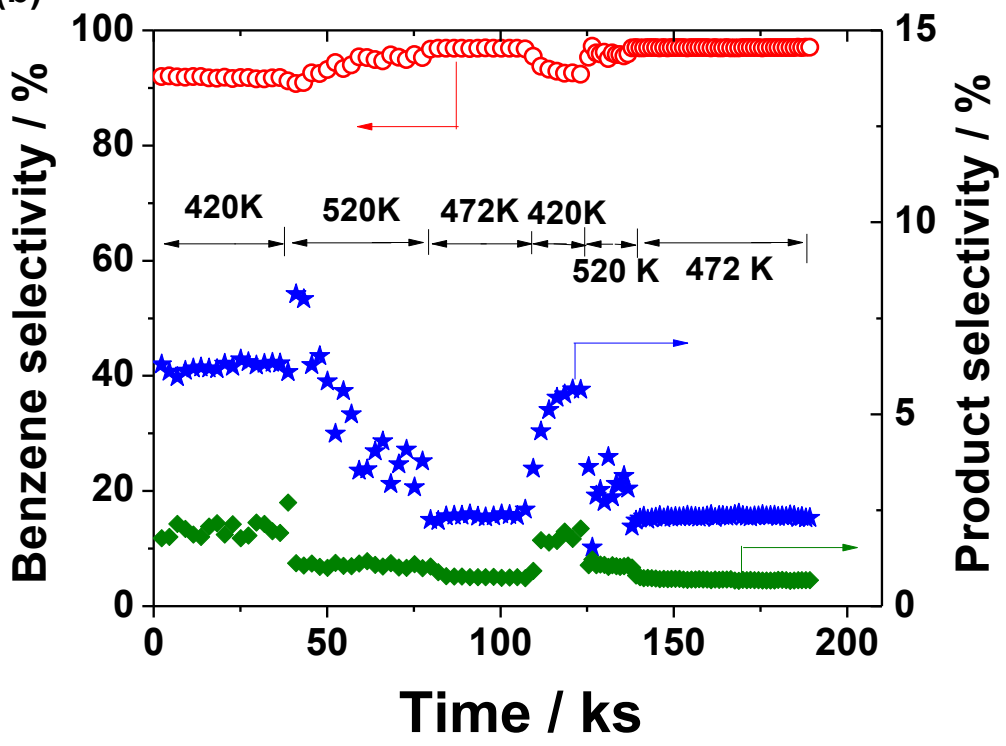

(c)

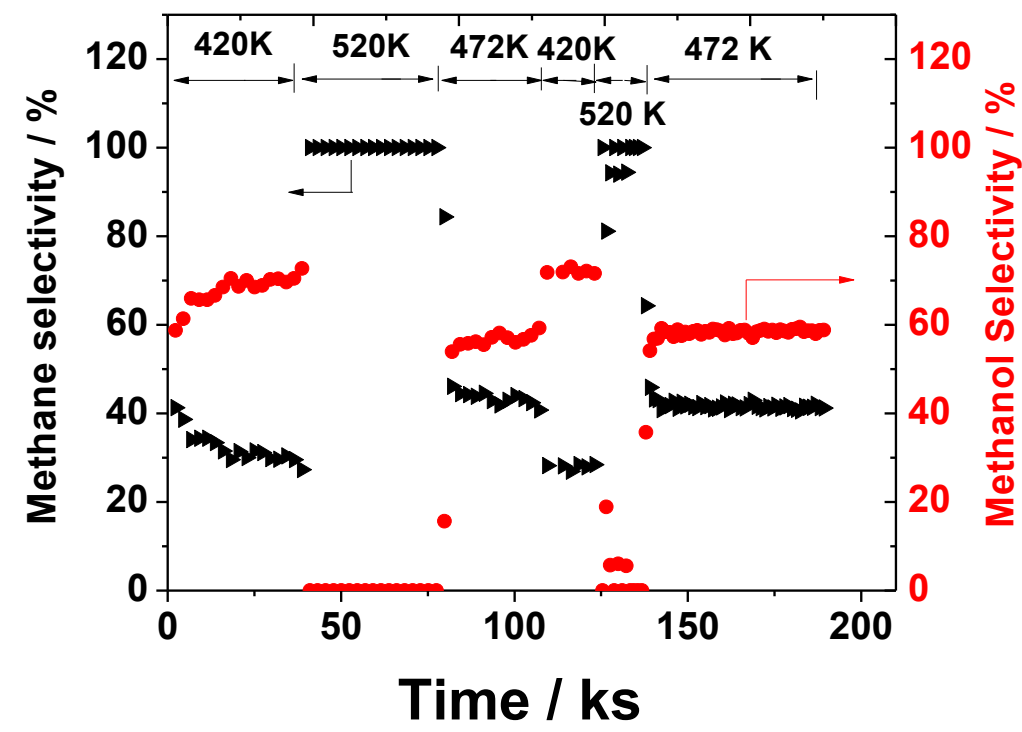


Fig. 5

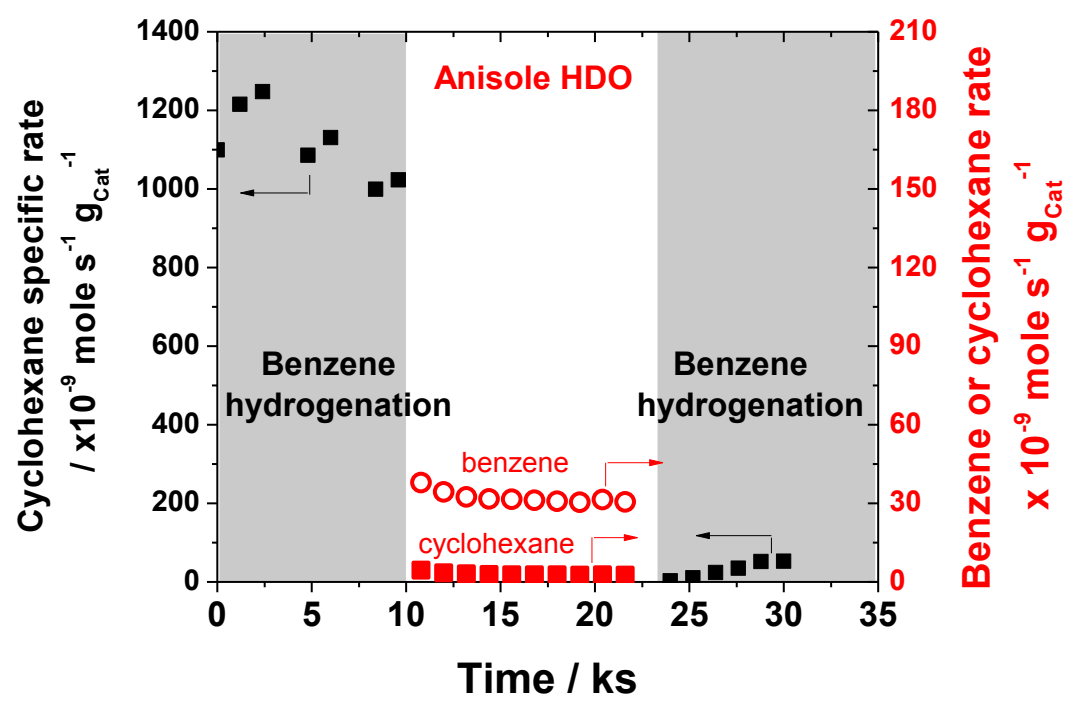

Fig. 6

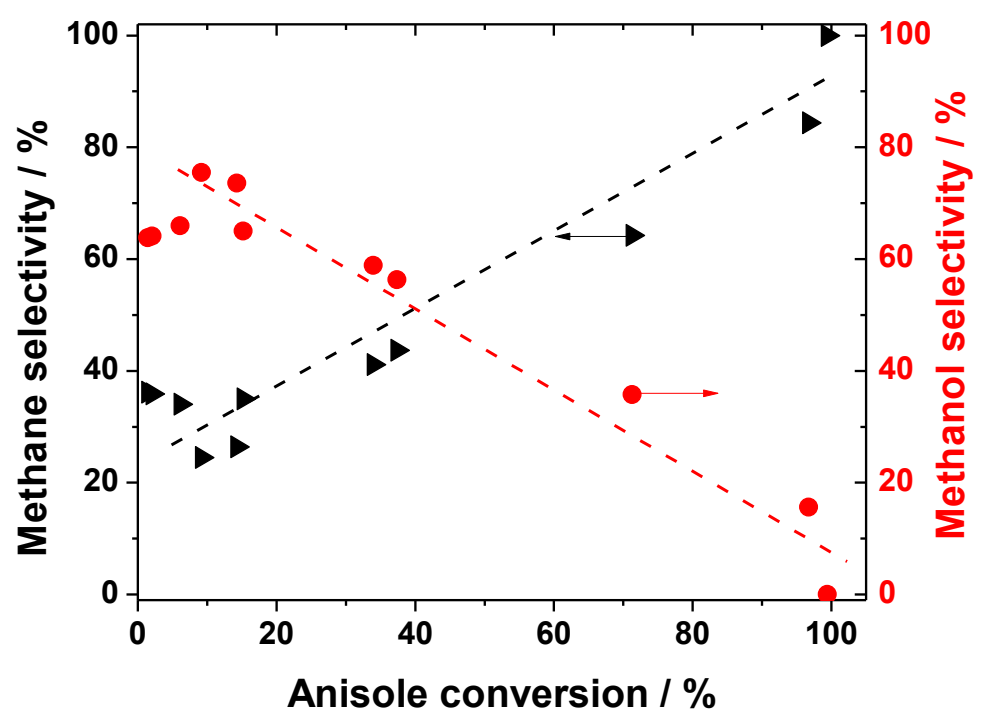


Fig. 7

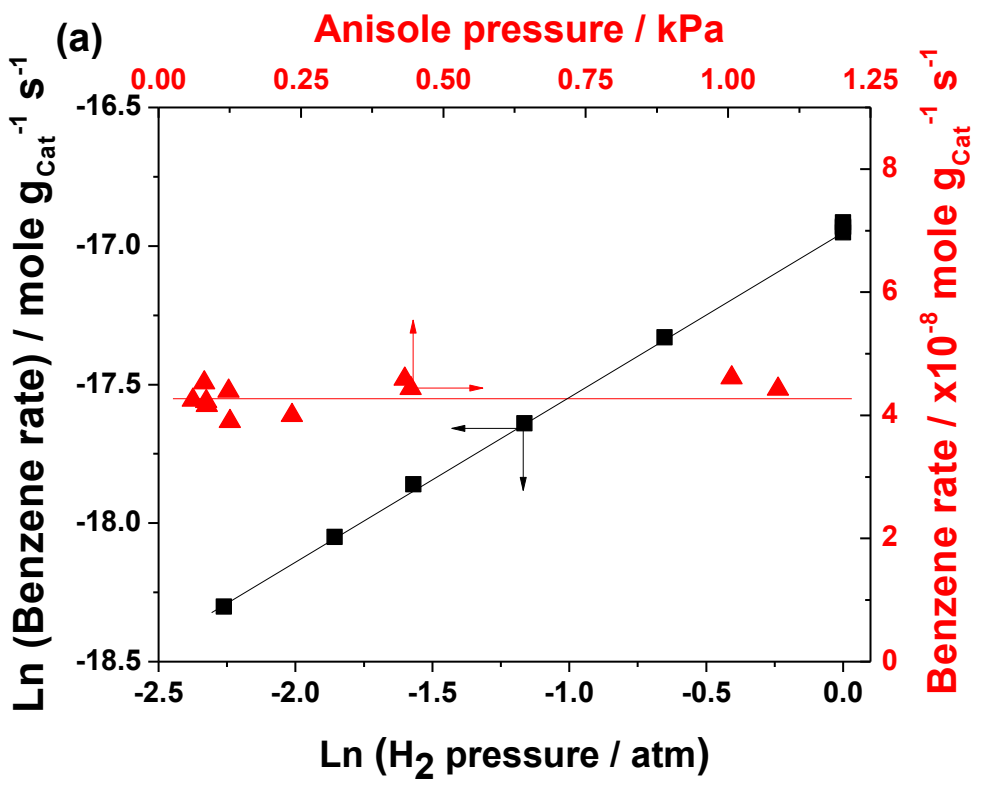

(b)

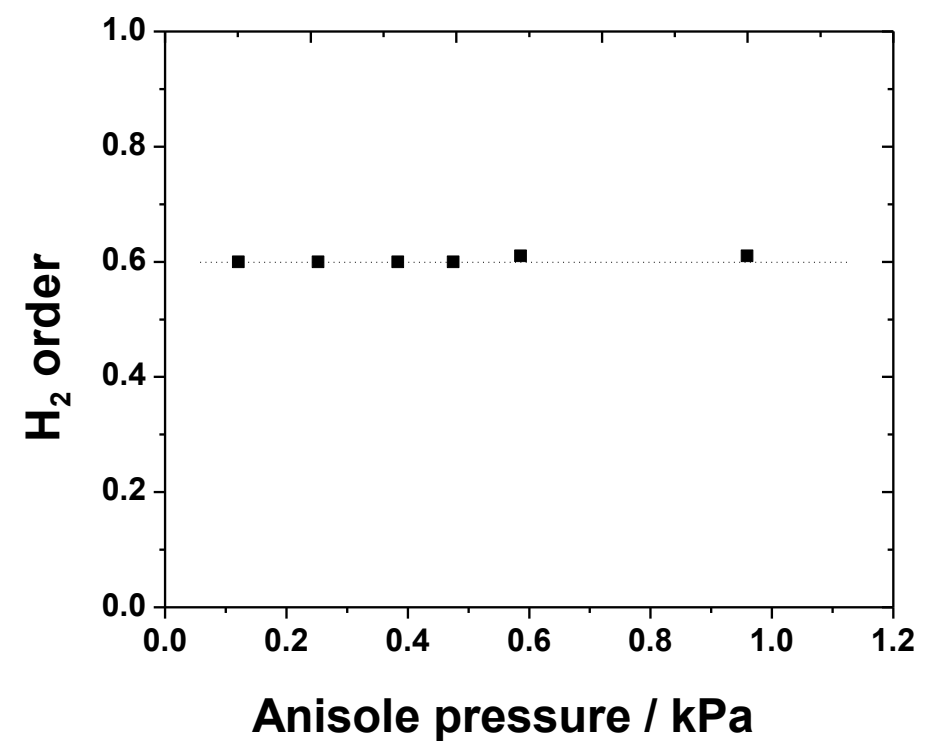


Fig. 8
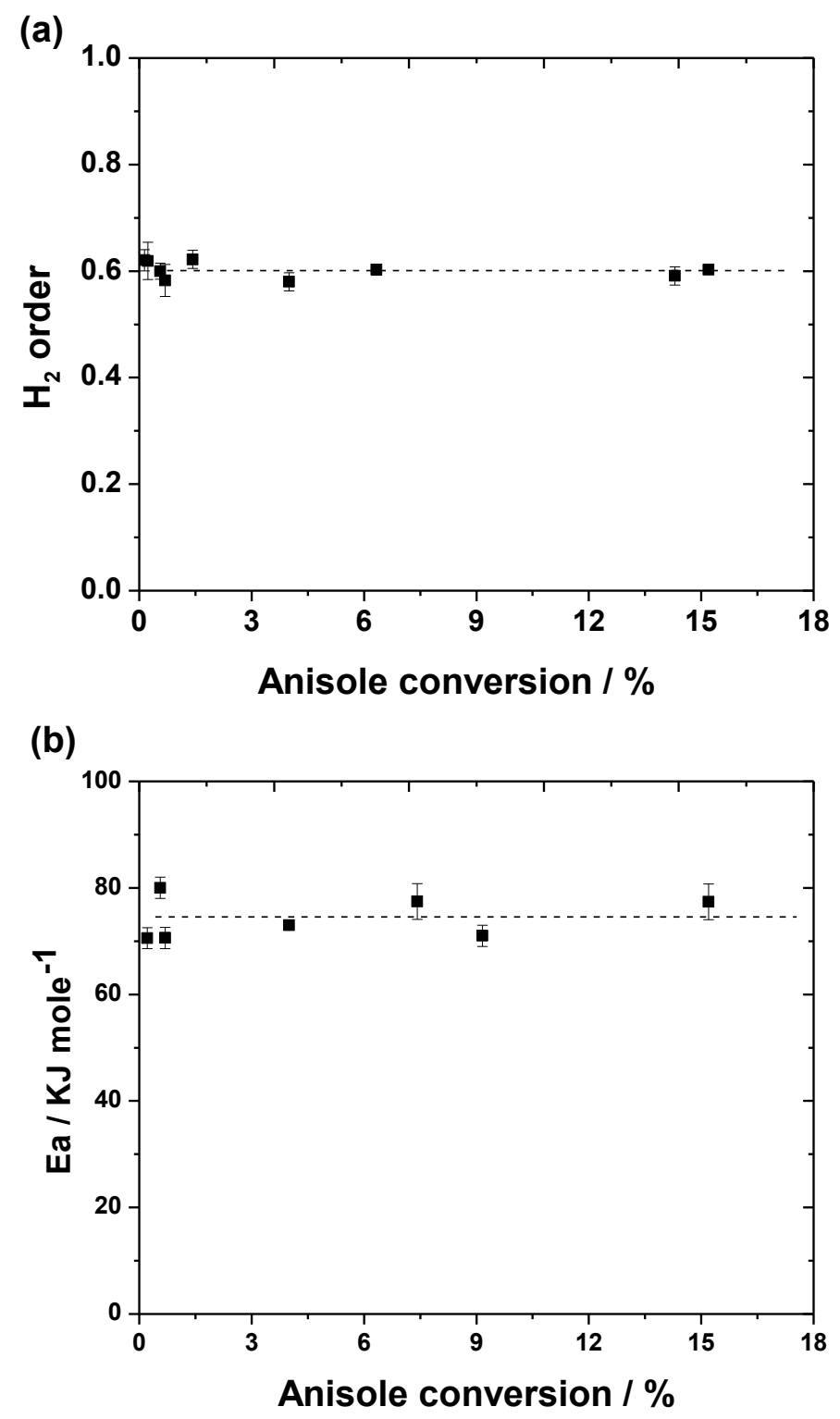
Fig. 9

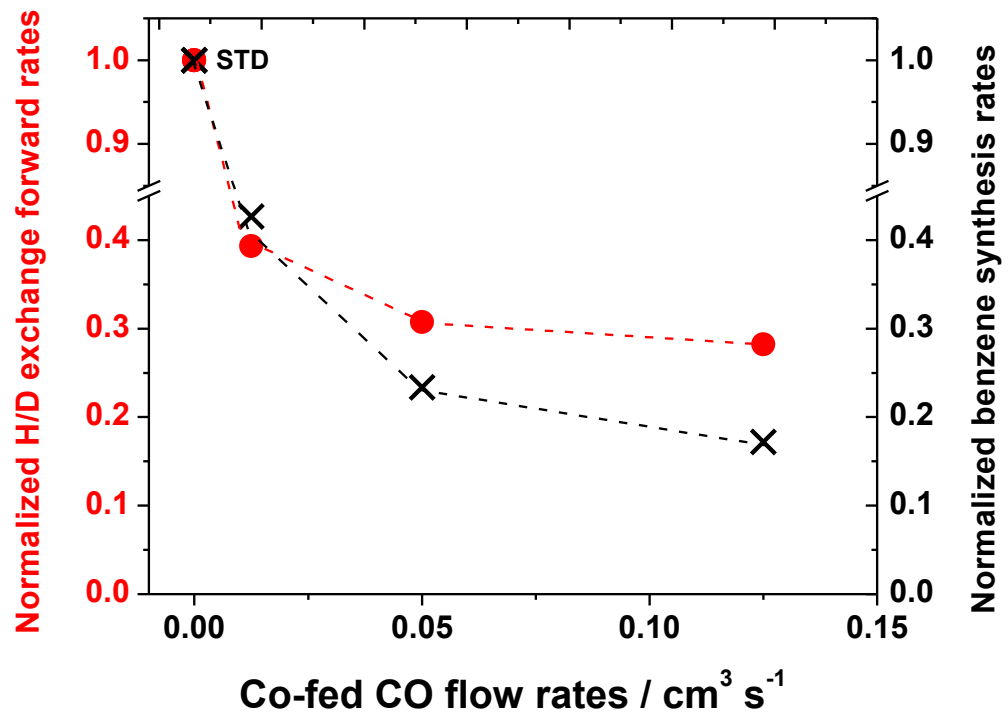

